\title{
The Role of Direct Strategy Instruction and Indirect Activation of Self-Regulated Learning-Evidence from Classroom Observation Studies
}

\section{Charlotte Dignath $^{1}$ (D) Marcel V. J. Veenman ${ }^{2}$}

Published online: 15 July 2020

(C) The Author(s) 2020

\begin{abstract}
Despite the consensus about the importance of self-regulated learning for academic as well as for lifelong learning, it is still poorly understood as to how teachers can most effectively support their students in enacting self-regulated learning. This article provides a framework about how self-regulated learning can be activated directly through strategy instruction and indirectly by creating a learning environment that allows students to regulate their learning. In examining teachers' instructional attempts for SRL, we systematically review the literature on classroom observation studies that have assessed how teachers support their students' SRL. The results of the 17 retrieved studies show that in most classrooms, only little direct strategy instruction took place. Nevertheless, some teachers provided their students with learning environments that require and thus foster self-regulated learning indirectly. Based on a review of classroom observation studies, this article stresses the significance of (1) instructing SRL strategies explicitly so that students develop metacognitive knowledge and skills to integrate the application of these strategies successfully into their learning process, and (2) the necessity of complementing classroom observation research with data gathered from student and teacher self-report in order to obtain a comprehensive view of the effectiveness of teacher approaches to support SRL. Finally, we discuss ten cornerstones for future directions for research about supporting SRL.
\end{abstract}

Keywords Self-regulated learning · Teacher · Learning environment · Strategy instruction · Classroom observation

Charlotte Dignath

dignath@dipf.de

1 Leibniz Institute for Research and Information in Education, Rostocker Straße, 660323 Frankfurt am Main, Germany

2 Institute for Metacognition Research (IMR), Hillegom, The Netherlands 
Despite a consensus between educational theory and practice about self-regulated learning (SRL) as a key competency for lifelong learning that learners should acquire from early schooling on (Levin 2003), it is still poorly understood as to how students can best be supported in acquiring this competency to self-regulate their learning. SRL refers to learners planning, monitoring, and controlling one's learning to make their learning more effective (Veenman 2017). SRL theory is built on the idea that the control of the learning rests with the learner, who regulates his/her actions to achieve a certain goal, such as for example task performance (Paris and Paris 2001). From empirical studies, training studies, experiments, theoretical papers, and meta-analyses can be derived that SRL is positively associated with learning behavior, achievement, and motivation (for an overview, see for example, Dignath and Büttner 2008; Donker et al. 2014; Hattie et al. 1996; Veenman 2013). Studies include all age groups of learners and all kinds of contexts, implying that every student should have the chance to learn how to self-regulate one's learning. Consequently, every teacher should be able to foster and facilitate SRL among her or his students. Recently, the focus of research on SRL shifted from directly training self-regulation in learners to training teachers in supporting their students' self-regulation of learning (e.g., Kramarski 2018; Kramarski and Kohen 2017). Despite evidence that teaching can improve SRL (e.g., Perry and Rahim 2011), it is still poorly understood how teachers can enhance SRL most effectively. Moreover, little is known about the teachers' intentions that guide their different approaches of supporting SRL in the classroom (e.g., Dignath and Büttner 2018).

\section{Self-Regulated Learning}

Self-regulated learners plan, monitor, and control their learning in order to reach a learning goal by enacting metacognitive strategies that support these regulation activities (e.g., Veenman 2017). In Nelson's (1996) metacognition model, students' learning processes are represented as taking place at two levels. On the object level, the learner's cognitive activities take place that are needed for the execution of a task. At the meta level, metacognitive activities take place that regulate the object level. As a result of monitoring processes, information about the state of the object level flows to the meta level. Based on the outcome of this monitoring information, regulatory commands from the meta level are transmitted back to the object level through control processes. Nelson's model describes metacognition as a bottom-up process in which monitoring is activated when interferences in task performance are recognized (Nelson 1996). In order to describe the active use of metacognitive strategies, Veenman (2017) extended Nelson's model by including the perspective of metacognition as a top-down process. Metacognitive activities are not merely triggered by task interferences (bottom-up), but also by a program of self-instructions at the meta level that is activated once the learner is faced with a more or less familiar problem (top-down). Such self-instructions could take place in terms of condition-action-rules, such as, "IF you encounter a task, THEN look for the task assignment and take notice of it" (Veenman 2017). With regard to Nelson's (1996) and Veenman's (2017) models, cognitive strategies are applied on the "executional" object level, while metacognitive strategies are positioned on the "executive" meta level (see Fig. 1). Metacognitive strategies can occur throughout the entire learning process (Flavell 1976). According to Zimmerman (1998), a self-regulated learning process involves three phases: (1) a forethought phase in which learners orientate on the task, set goals, and plan learning activities; (2) a performance phase in which learners monitor for errors and mistakes and for progress being made during task execution; and (3) a reflection phase in which learners evaluate their outcomes and reflect on how to proceed. The learners' conclusions from this reflection phase may have an impact on their self-concept. The 


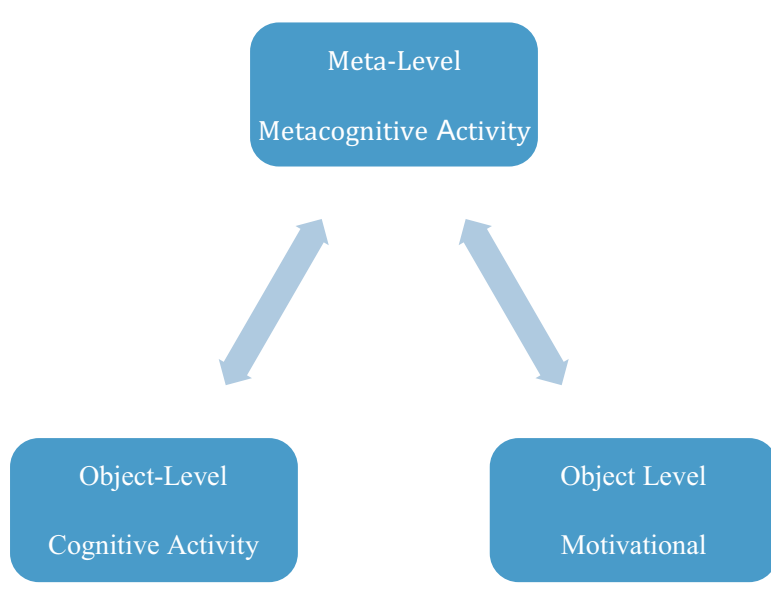

Fig. 1 The relation between cognitive, motivational, and metacognitive activity, based on Nelson (1996)

outcome of a learner's self-evaluation affects a subsequent forethought phase, leading to the cyclical nature of the model. Therefore, the SRL process is illustrated in terms of a feedback loop, involving a cyclical process of evaluating the effectiveness of applied strategies, and reacting to this feedback with motivational, behavioral, or metacognitive responses. Feedback can lead to a change in the perception of the learner's knowledge or self-esteem, thus affecting the learner's motivation to further engage in strategic behavior. At the behavioral level, it can result in a modification of the cognitive strategy being used (Zimmerman 1990). In addition, monitoring during the performance phase also contributes to the cyclical nature of SRL (Veenman 2013). When a student struggles in the performance phase, monitoring may incite the learner to re-orient on the task at hand and, thus, return to the forethought phase. The same applies to a negative outcome of evaluation in the reflection phase (Veenman 2013).

During the SRL process, application of metacognitive strategies interacts with motivational processes as well as with the use of cognitive strategies (Boekaerts 1999). The use of cognitive strategies serves to facilitate the execution of the task. Hence, cognitive strategies are considered learner activities that are intended to influence how the learner processes information, for example by summarizing the most important information in a text in order to improve text comprehension (Weinstein and Mayer 1986). As metacognition directs cognitive activities, metacognitive activities cannot take place without carrying out cognitive activities (Veenman 2017). Consequently, it is hard to disentangle cognition and metacognition in learner behavior. For example, a learner who is checking the outcomes of a calculation has taken the decision to do so and to choose this cognitive strategy at the meta level. In this example, orientating oneself in order to understand which cognitive strategy has to be applied, and planning to apply the cognitive strategy of checking one's outcome, are metacognitive strategies. The execution of the chosen cognitive strategy, however, takes place at the object level (see Veenman et al. 2006). Metacognitive strategies influence the choice of an adequate cognitive strategy and serve to control and monitor the application of this strategy. Whereas cognitive strategies are applied to perform a task, metacognitive strategies are needed to understand how the task has to be performed in an orderly way (Garner 1987). Whether cognitive and metacognitive strategies will be used also depends on the motivational conditions. Motivational processes, such as self-efficacy and goal setting, play a role in SRL by influencing the initiation and maintenance of learning behavior (Efklides 2011). Students who are not motivated for, or who do not see the need for using strategies, are not likely to abide with the instruction of those strategies by 
their teachers. Applying new strategies may cost students more time and effort than their habitual learning would do. It is therefore important for learners to be motivated to use these strategies (Veenman 2013). The motivation of learners to use cognitive and metacognitive strategies will depend on their metacognitive knowledge, i.e., their knowledge about how and when to use a strategy, their awareness of the benefit of strategy use, as well as on their self-efficacy, i.e., feeling able to use a strategy (Veenman 2011). Thus, SRL arises when knowledge about strategies and the motivation to use strategies co-occur (McCombs and Marzano 1989; Paris and Paris 2001).

\section{The Present Study}

In order to derive future directions for research about teachers' promotion of SRL, we pursue two goals in this review article. Firstly, based on theories about direct strategy instruction and powerful learning environments, we present a framework of direct and indirect approaches to activate SRL. More precisely, we discuss theoretical grounds for different ways of direct strategy instruction and we describe instructional elements of the learning environment that foster students' SRL in an indirect way. Secondly, we provide an overview of classroom observation research regarding teachers' support of SRL, since there is evidence as to the validity of score interpretations drawn from classroom observations to assess teachers' instructional practice (e.g., Brophy 2006; Pianta and Hamre 2009; Schaffer et al. 2014). Combining these two goals may provide new insights into different aspects of teacher practices and their competence to foster SRL in relation to student outcomes. As there is a lack of review studies synthesizing research on teachers' promotion of SRL quantitatively, this overview does not pretend to present a complete state-of-the-art in the field of teachers' promotion of SRL. As a conceptual paper, it will review specific studies that have applied classroom observations as a method to assess teachers' SRL practices, which allows for a better comparison between findings of studies. Based on a review of classroom observation studies, this article stresses (1) the significance of instructing SRL strategies explicitly so that students develop metacognitive knowledge and skills to integrate the application of these strategies successfully into their learning process, and (2) the necessity of complementing classroom observation research with data gathered from student and teacher self-report in order to obtain a comprehensive view of the effectiveness of teacher approaches to support SRL.

\section{A Framework on Teacher Approaches to Activate Self-Regulated Learning}

In order to enable and to motivate students to self-regulate their learning, teachers can promote strategies directly, and they can indirectly activate SRL by providing a learning environment that incites students to self-regulate their learning. In the following, we will provide an overview of research that has been conducted to investigate the direct promotion of strategies and the indirect activation of SRL in the school context (see Fig. 2).

\section{Direct Instruction of Strategies}

Helping students to self-regulate their learning includes teaching them metacognitive strategies directly (Pressley et al. 1992). Intervention studies in the academic context have shown that 


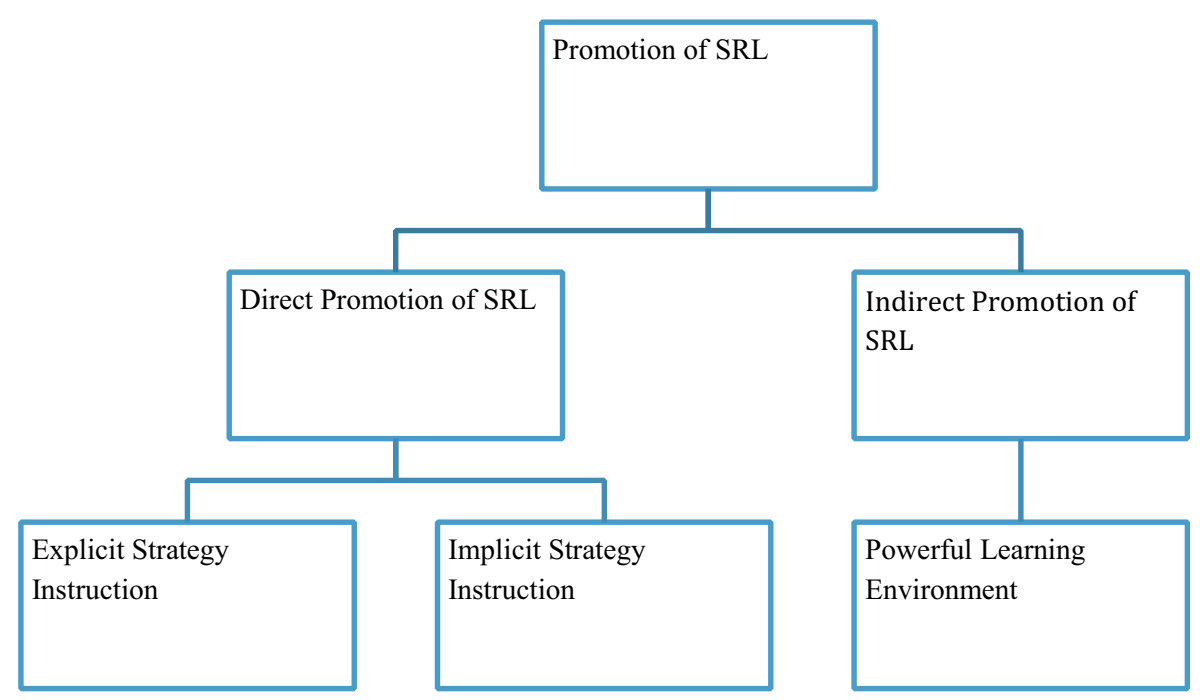

Fig. 2 Teacher behavior regarding the promotion of SRL

SRL can be effectively supported by means of strategy training (Dignath and Büttner 2008; Dignath et al. 2008; Donker et al. 2014; Hattie et al. 1996). In order to support learners in transferring their strategy knowledge to the learning context, the integration of strategy instruction with learning content has been endorsed years ago (e.g., Hattie et al. 1996; Veenman et al. 1994; Volet 1991). Such "embedded" instruction allows students to bring the application of metacognitive strategies in line with task demands by deciding which activity needs to be performed when in the context of a specific task (Veenman 2013). Consequently, extracurricular intervention research has rather been replaced by intervention research that has been integrated within the school context (see Dignath et al. 2008). Such research on strategy instruction can be divided into three lines: In a first line of research, the proximity to real-school context has been increased by providing real classroom teachers with materials to implement strategy training in their classrooms, instead of providing students with extracurricular strategy training. Successful intervention indicated that teachers can effectively promote strategies necessary for SRL after being provided with adequate materials that they can use during their teaching (e.g., Askell-Williams et al. 2012; Leidinger and Perels 2012; Perels et al. 2009). In a second line of research, in-service teachers received training on how to foster their students' SRL, instead of receiving classroom materials. The aim of this line of research has been to support teachers in preparing their instructional material themselves. Such teacher intervention studies have proven successful in preparing teachers to deliver strategy instruction in their classrooms (e.g., Finsterwald et al. 2013; Kramarski and Revach 2009; Perry et al. 2008; Veenman 2018). A third line of research has integrated SRL intervention into initial teacher training in order to activate preservice teachers' own self-regulation of learning and teaching, and to implement the promotion of SRL already early in teacher education (e.g., Kramarski and Kohen 2017; Kramarski and Michalsky 2010; Perry et al. 2008; Zohar et al. 2001).

The results of strategy instruction research have indicated that direct strategy instruction can be enacted in various ways that differ substantially in the degree of explicitness (e.g., Dignath and Büttner 2008; Veenman 2011. The distinction between explicit and implicit strategy 
instruction has been introduced by Brown et al. (1981), who differentiated three levels of strategy instruction: on the lowest level, the so-called blind training, students are induced to use a strategy without providing them with any information about the significance of this activity. The students are not told why to use a certain strategy, in which situations this activity is appropriate, or even that this activity is a strategy. The blind training corresponds with implicit strategy instruction. Although this can enhance the children's use of the intended activity, it might fail to maintain its production in the future and its generalization to similar useful contexts. On an intermediate level, the informed training, students are both induced to apply a certain strategy, but are also provided with information about the significance-i.e., benefits or usefulness - of this strategy (Veenman 2013). This type of training should result in improving the performance, as well as in maintaining this activity when faced with a similar subsequent problem. And finally, the self-control training, the highest level of instruction, combines the informed training with an explicit instruction of how to manage, monitor, check, and evaluate strategy application. This type of training best facilitates the transfer of strategy application to appropriate settings (Brown et al. 1981; Veenman 2018). Informed and selfcontrol training help students to execute and maintain particular metacognitive strategies, with self-control training making students more flexible in applying the strategies to various contexts (Brown et al. 1981). Thus, explicit instruction means that the teacher clearly instructs the students about a strategy by explaining and demonstrating how to execute a particular strategy, clarifying benefits of strategy use, and supporting students in strategy application (see Table 1). This is referred to as the $W W W \& H$ rule for strategy instruction, denoting What to do, When, Why, and How (Veenman 2013; Veenman et al. 2006). The teacher provides students with information about the application of a certain strategy in order to help them develop metacognitive knowledge (e.g., Dignath and Büttner 2008; Dignath-van Ewijk et al. 2013).

Implicit instruction can be an effective way of stimulating strategy use once students are already experienced in using a certain strategy (see Table 2). However, students first have to be trained in self-regulation strategies explicitly in order to benefit from implicit instruction and modeling (Harris et al. 2013; White and DiBenedetto 2015). However, research has shown that the instruction of learning strategies does not necessarily improve learning outcomes, strategy use, or motivation. Students also need to receive feedback on their strategy use (Zimmerman 2002), and they need to have metacognitive knowledge about strategies and to reflect on the benefit of using them in order to be able to successfully apply them (Schraw

Table 1 Examples of explicit strategy instruction (always combined with at least informed instruction about its usefulness, as blind training cannot be distinguished from implicit training)

Explicit demonstration

Explicit explanation

Explicit call (request)

Explicitly asking (like questioning-developing classroom talk)
The teacher demonstrates a certain strategy by explicitly referring to the activity as a strategy. He/she shows the students how to apply the strategy and gives explanations about its usefulness.

The teacher explains why and how to use a strategy, but does not demonstrate its application. He/she explains, for instance, when to apply a strategy, what the benefits are of the strategy, and how to proceed while using it. S/he explains in detail what to do and how to do it, and possibly gives examples.

The teacher explicitly asks the students to use a certain strategy. The relevance of the activity as a strategy has to become clear to the students.

The teacher asks the students if, how, when, and why they have applied certain strategies in order to develop metacognitive knowledge about strategies and their application. 
Table 2 Examples of implicit strategy instruction

Implicit demonstration $\begin{array}{r}\text { The teacher applies a strategy without explicitly mentioning it. He/she demonstrates } \\ \text { the strategy without pointing it out or giving any explanations about it. } \\ \text { The teacher invites the students to read an explanation for a strategy (from the book, a } \\ \text { slide etc.). Similar to "explicit explanation," but the teacher still does not present the } \\ \text { explanation him/herself and students have to take notice of it on their own. }\end{array}$
$\begin{aligned} & \text { Implicit call (stimulative } \\ & \text { nature) }\end{aligned}$
$\begin{array}{r}\text { The teacher reminds the students to apply a certain strategy without explicitly } \\ \text { requesting the use of this strategy. Nevertheless, the hint implicates an unexpressed } \\ \text { request. }\end{array}$
$\begin{array}{r}\text { The teacher does not explicitly ask questions about a strategy or its application. } \\ \text { However, the topic/problem refers implicitly to a certain strategy. }\end{array}$

1998; Veenman et al. 2006). The outcomes of meta-analytic research have demonstrated that enabling learners to reflect on their use of metacognitive strategies leads to larger effects of strategy training (Dignath et al. 2008; Dignath and Büttner 2008; Donker et al. 2014; Hattie et al. 1996). Such metacognitive reflection about strategy use includes two aspects, as learners (1) need to master the skill of applying a learning strategy, and (2) need to have the will to engage in SRL (McCombs and Marzano 1990). (1) More precisely, this means that in order to develop the skills for SRL, learners need to acquire metacognitive knowledge. Thus, they need information about how to use strategies, and about conditions under which a certain strategy is most useful in order to learn the skill (e.g., Butler 2002; Schraw 1998). Through explicit instruction, teachers help students to reflect about their own strategy use on a meta level (see Nelson 1996), and to apply strategies in an effective way (see Veenman 2017). Reflecting on strategy use can also help to transfer the application of a certain strategy to another task or even another subject area (Veenman 2018). (2) Additional to metacognitive strategy knowledge, students need to learn how they benefit from using a certain strategy, thus, to build up a motivation for using strategies. Investing additional time and effort for strategy use requires motivation from the learner (Efklides 2011). This is more likely to happen once students know that it will help them to save time and improve their performance. Once students are prepared for SRL, they need learning environments that allow them to enact and practice SRL (e.g., White and DiBenedetto 2015).

\section{Indirect Activation of SRL}

Beside the intervention research on how to instruct strategies, another field of research has been investigating how SRL can be fostered in a subtler way than through direct strategy instruction, namely by creating learning environments that require learners to self-regulate their learning, without providing strategy training (e.g., Perry and Rahim 2011). As SRL draws on social-constructivism, one can assume that learners actively take part of their learning process by constructing their knowledge (Zimmerman 2000). Providing students with constructivist learning environments is therefore essential in helping students to become selfregulated learners (e.g., Hmelo-Silver et al. 2007). A framework for learning environments, which are strongly related to the indirect encouragement of SRL, has been described by De Corte et al. (2004), who derived four aspects of learning environments from constructivist learning theory: (1) activating prior knowledge \& creating cognitive conflict, (2) learning in context, (3) cooperative learning, and (4) self-directed learning. In the following, we will show how these aspects are grounded in educational and psychological learning theory, and how they relate to the activation of SRL. 
(1) In order to stimulate SRL, learning cannot take place in a passive and receptive way, but through an active construction of associations with one's prior knowledge (Limón 2001). Prior knowledge is essential for learners to understand the task and the goals of the task (Eilam and Aharon 2003). In this way, the activation of prior knowledge facilitates the learner to monitor (Butler and Winne 1995), and to formulate challenging goals (Dembo and Eaton 2000). In order to encourage active participation in knowledge construction, research has shown that students should work on complex, less structured, or open problems, which can be solved only through a deeper understanding of the topic (Dolmans et al. 2005).

(2) In addition, SRL can be supported when the situatedness of learning is taken into account by providing learning situations that highly correspond to the application (Resnick 1987). Learning situations are often more theoretical and abstract compared to situations of application. This increases the effort of the learner to transfer the knowledge from the learning situation to a real-life application of the knowledge. Therefore, knowledge often remains inert (Renkl et al. 1996). Hence, the situatedness of the learning situation is initially needed for the acquisition of knowledge. Next, the acquired knowledge should be abstracted and detached from the context in which it was initially learned, which serves as a basis of transfer (Salomon and Perkins 1989).

SRL can also be supported by providing cooperative learning environments that stimulate students to exchange about different perspectives toward the learning content (Vosniadou et al. 2001); for example, Jigsaw (Aronson 1978), or Student TeamsAchievement Divisions (STAD; Slavin 1995). Research has shown that cooperative learning can facilitate learning, and in particular SRL (e.g., Souvignier and Mokhlesgerami 2006), especially in complex tasks that produce a high cognitive load. The cognitive resources of several learners can share the burden of the load (Kirschner et al. 2009). Over the last 15 years, new models of socially shared regulation of learning (SSRL; Hadwin et al. 2011; Molenaar et al. 2011) have added the description of social processes to the individual process of SRL. Additional to regulation of task performance, $S S R L$ describes regulatory processes within the interactions between the group members (for a review, see Panadero and Järvelä 2015).

(4) Finally, a student-directed learning environment enables students to participate in the planning, selection, and accomplishment of learning activities (Perry and Rahim 2011). Self-determination flourishes when a more or less structured learning environment allows for effective autonomy in students (Deci and Ryan 1985, 1993). Thus, internal control by the student and external control by the teacher should be balanced. To enable self-determination in students, teachers alternate between guiding through direct instruction and coaching when needed (White and DiBenedetto 2015). In the latter capacity, they monitor the adequacy of student decisions, and they are available for consultation when students face problems. Instructional elements - such as individualized instruction, working with weekly schedules, problem-based learning on projects, or interdisciplinary learning - can offer opportunities for self-determination (Van de Pol et al. 2010).

In line with these approaches to activate SRL indirectly, Perry's research (e.g., 1998; 2013; 2015) has demonstrated that there are several instructional elements of learning environments that are relevant for students' engagement in SRL: (a) offering complex and meaningful activities; (b) providing choices about the content, the place, or the cooperation partner while 
working on an assignment; (c) providing choices about the level of challenge, i.e., about how much to do, at what pace, and with what level of support; and (d) providing evaluation criteria. These instructional elements have proven to distinguish between classrooms that support students in enacting SRL and those that do not (e.g., Perry et al. 2002, 2006). For example, Butler et al. (2013) supported teachers in using more inquiry-oriented or problem-based learning approaches in order to engage their students in authentic learning tasks. This should provide the foundation for students to integrate both content and process learning. They found student achievement gains to be associated with teachers who stimulated independence during learning through inquiry-oriented and problem-based learning (Butler et al. 2013). Contrary to the research area on strategy training described above, these studies did not focus on direct strategy instruction, but on an indirect support of SRL by creating conditions conducive for SRL (see Table 3).

Drawing on research of the instructional quality of classroom teaching, the here-mentioned instructional elements, which are conducive to SRL, can be traced back to generic models of teaching effectiveness that have been derived from meta-analyses (e.g., Scheerens et al. 2007; Seidel and Shavelson 2007), and from longitudinal student assessment studies (e.g., Hiebert et al. 2003; Klieme et al. 2009). Although the support of SRL is not explicitly in the focus of research on high-quality instruction, most frameworks of teaching effectiveness embrace

Table 3 Preconditions of the learning environment that enhance SRL

\begin{tabular}{ll}
\hline Classroom example & Preconditions
\end{tabular}

Self-direction

The teacher allows the students to take responsibility for - How often do students get responsibility through structuring their learning by giving them some decision-making freedom.

There is a balance between self-directed and teacher-directed learning. freedom of choice?

- How (often) are self-directed and teacher-directed learning attuned to the students' needs? (quality)

Cooperative learning

The teacher uses forms of cooperative learning during class.

The teacher takes care that the students really work together cooperatively and intervenes when necessary.

- Do students work collaboratively?

- If yes, how often (quantity)

- If teacher activates students to collaborate

- If teacher monitors the students while working together

- Adequacy of support provided by the teacher when necessary (quality)

Constructivist learning principles

The teacher prompts the students to activate prior knowledge and to integrate new knowledge.

The teacher integrates new knowledge in a meaningful context and/or introduces new knowledge by creating a cognitive conflict.

The teacher gives complex and/or open and/or marginally structured problems which can be handled in different ways and/or allow for several solutions.

Fostering transfer

Learning is integrated in a real-life context.

The teacher illuminates the learning contents in diverse contexts and/or with various ways of looking at a problem.
- How often is it observed and how clearly can it be observed?

- To what extent is the teacher attempting to do so?

- How often are 'real' problems presented by the teacher and how clearly can it be observed?

- To what extent does that apply?

- To what extent are multiple perspectives presented? 
similar concepts, characterized by organizational, social, and instructional processes (Eccles and Roeser 2010), or by teaching decisions regarding classroom management, motivational atmosphere, and curriculum and instruction (Pressley et al. 2001). In line with this categorization, Hamre and Pianta (2009) presented the CLASS framework (Classroom Assessment Scoring System; Pianta et al. 2008) that includes three domains: classroom organization, emotional support, and instructional support. Similarly, Klieme et al. (2009) derived three basic dimensions of teaching quality-classroom management, student support, and cognitive activation - from the data of the TIMSS and PISA studies (see also Praetorius et al. 2018). Classroom management covers how a teacher handles classroom disruptions, discipline, and clarity of rules by identifying and strengthening desirable student behaviors, and preventing undesirable ones (Kounin 1970). Through classroom management, teachers can create effective learning opportunities that enhance time on task (e.g., Seidel and Shavelson 2007) and student motivation (e.g., Rakoczy et al. 2007). Thus, classroom management can be seen as a precondition for the enactment of the constructivist instructional elements mentioned earlier that support SRL. Secondly, teachers' student support builds on research about classroom climate and social interactions, as well as about teachers' adaptive support of the learning process (i.e., their diagnostic competence, a positive culture of errors, and individual learning support (Praetorius et al. 2018)). As shown earlier, scaffolding plays an important role in fostering students' SRL (see Collins et al. 1991). Finally, among the three dimensions, cognitive activation is most closely aligned with the above-mentioned instructional elements to activate SRL. Following constructivist theories of learning, cognitive activation aims at enhancing conceptual understanding as well as students' engagement with the learning content (e.g., Hiebert et al. 1997) by exploring and building on students' prior knowledge, by stimulating cognitive conflict, by activating higher-order thinking processes, and by fostering students' metacognition (e.g., Baumert et al. 2010). Although little research has been carried out to date that has brought together general features of teaching quality with SRL, the few studies available have indicated that these three dimensions of teaching quality are associated with students' SRL (Rieser et al. 2016), and - inversely - that a professional development course for teachers about promoting SRL not only affects specific instructional elements for SRL but also generic teaching quality (Werth et al. 2012).

\section{Developing Self-Regulated Learners}

Several researchers have provided suggestions to support the development of selfregulating learners that can be distinguished in their degree of how explicit the activation of regulation strategies takes place. Most models have in common that they assume the teachers' efforts in supporting the students to change over time are in accordance with the developmental level of the students (e.g., Schunk 2008; White and DiBenedetto 2015; Zimmerman 2002). Such adaptive scaffolding has been described by Collins et al. (1991), who differentiated among four different aspects of apprenticeship that can serve to instruct strategies: modeling, scaffolding, fading, and coaching (Cognitive Apprenticeship; Collins et al. 1991). In modeling, the students watch the teacher using a certain strategy. The student learns to use the strategy by observing the teacher in terms of modeling (Bandura 1986). Scaffolding implies that the teacher adapts his or her support to the needs of the student who is carrying out a task. In fading, the teacher slowly removes his or her support and gives more and more responsibility to the student. Finally, coaching comprises the whole process of 
apprenticeship instruction, including the choice of tasks, providing students with hints, scaffolding, giving feedback, and structuring the procedures of the learning process. In the same vein, Zimmerman $(2000,2002))$ describes four levels of self-regulation that teachers use in order to support students' development of SRL: (1) At the observation level, teachers control the pacing of the learning by demonstrating and verbalizing regulatory actions and thoughts. (2) At the emulation level, the students attempt to follow the behavior that has been modeled by their teacher or peer. At this stage, it is the teacher's role to support and encourage the student and to provide feedback. (3) When students proceed to practice what was learned without further input by teachers, they have entered the level of self-control. At this level, teachers can provide learning environments that allow the students to gradually take over responsibility for their learning and to deliberately practice the use of a learning strategy. (4) At the selfregulation level, the students monitor their behavior, and are able to adjust their learning systematically to changing requirements and conditions. Now the teacher can offer a learning environment that allows the students to perform without teacher supervision, and only provides assistance when requested (Zimmerman 2000, 2002). Both approaches have in common that teacher control of the learning process is reduced as students move to the next self-regulatory level (see also Salonen et al. 2005). Observational learning is supposed to be guided and scaffolded by the teacher (White and DiBenedetto 2015). Nevertheless, the modeling of strategy use can take place implicitly if the teacher supports the student in learning SRL without explicitly addressing strategy use. In this regard, implicit means that the teacher demonstrates a procedure without verbalizing what he or she is doing or without mentioning why a certain strategy is useful. The teacher does not necessarily provide the students with metacognitive information about strategy use and its benefits during modeling. Examples of implicit strategy instruction can be found in Table 1. Modeling, scaffolding, fading, and coaching can be implicitly used, but they may become explicit once the teacher addresses metacognitive aspects of strategy use. Regarding such adaptive scaffolding, there is a consensus that learners first need to learn regulation strategies before they can regulate their learning effectively (Corno 2008). The more students are trained in using self-regulation strategies, the more teachers need to provide learning opportunities that allow students to practice self-regulation. After modeling or observation, students will deliberately practice how to apply regulation strategies. This first take place under the supervision of their teachers, but teachers will gradually fade their scaffolding (Perry and Rahim 2011). The concepts of such constructivist principles require some guidance, at least for learners who are not experienced in self-regulation yet. Complex learning environments that contain much information, but only minimal structure or guidance, will be detrimental for learning since they increase cognitive load (Kirschner et al. 2006). There is evidence that metacognitive support can prevent students from experiencing high cognitive load (e.g., Kuensting et al. 2013), and that constructivist learning environments, such as problem-based learning, are more effective for learning when they provide explicit guidance (Wijnia et al. 2014).

Most research on teachers' support of SRL has focused on either direct or indirect activation of SRL, although the models of learners' SRL development described above imply that both are interacting in order to support students' SRL adaptively (see also Pressley et al. 1992). Based on the framework presented here, we will provide empirical evidence about teachers' attempts to foster SRL by considering both, direct and indirect approaches of 
teachers' SRL practice. To this aim, we review the literature on classroom observation studies about teachers' direct and indirect instructional practice to support SRL.

\section{Classroom Observations of Teachers' Approaches to Foster Self-Regulated Learning}

The second aim of this paper is to systematically review classroom observation research focusing on teachers' activation of SRL and to provide an overview of the field. Studies conducted to investigate teaching practice are usually based either on teachers' self-report or on classroom observation methods. Regarding teachers' SRL practice, self-report consists mainly of teacher questionnaires that assess how teachers perceive their teaching for SRL (e.g., Lombaerts et al. 2009). Although questionnaires can be administered economically to large groups, and their analyses are efficient regarding time and costs, off-line self-reports can suffer from validity problems (see Veenman 2011, or Veenman and van Cleef 2019 for an overview): First, teachers have to reconstruct their earlier teaching behavior from memory, and their retrieval might fail or be biased. Second, the administered questions might evoke biased answers, either due to social desirability, or because the described teaching behavior might create an illusion of familiarity. And finally, teachers have to value certain teaching activities by comparing themselves to other teachers, but they might vary in the reference point chosen for doing so. The latter likely impedes the comparability of results across teachers, and even within one teacher across several measurement points (Veenman and van Cleef 2019). Thus, self-report data alone has proven insufficient when attempting to understand the complex interplay of SRL in real classroom contexts (Perry and Winne 2006). As an alternative, classroom observations offer more suitable ways to capture teachers' instructional practice to support SRL (Butler 2002; Perry 2002; Perry et al. 2002). Contrary to offline measures, observations are not relying on introspection and the associated validity problems (Veenman and van Cleef 2019). Classroom observations, however, are also subject to certain limitations. Like other online assessments, they are time-consuming, which hinders the assessment of a larger teacher sample. Moreover, observations only capture the overt behavior, but not the underlying mental processes (Veenman and van Cleef 2019). For instance, Dignath and colleagues (2013) have shown that classroom observations about teachers' SRL practice were not necessarily associated with teachers' or students' estimation about their SRL practice, but teachers overestimated their SRL practice compared to observations and student ratings. Consequently, teachers might have different teaching intentions than what becomes overt in their teaching behavior, and these intentions are not captured by observations only (Dignath et al. 2013). Yet, observations show what teachers actually do in their lessons. Accordingly, classroom observation seems a suitable method to assess teachers' approaches to foster SRL, but it restricts the sample size and requires supplementary assessment of teachers' mental processes. To prevent the validity problems associated to self-report data, we restricted our review to studies that have applied classroom observations to assess teachers' SRL practice. In order to advance research about teachers' promotion of SRL, this systematical review addressed the following research questions:

(1) How do teachers attempt to promote SRL among their students?

(2) How is teachers' SRL practice related to student outcomes?

(3) Which teacher characteristics predict teachers' SRL practice? 


\section{Method}

\section{Eligibility Criteria}

The literature search was restricted to studies that met the following eligibility criteria: Firstly, articles had to provide empirical data from classroom observations focusing on teachers' SRL practice, as well as quantitative or qualitative analysis of this observation data. Secondly, studies had to be based on theoretical models of SRL or metacognition. Thirdly, studies were to be conducted in an educational setting, such as kindergarten, primary or secondary school, compulsory education, or higher education. Finally, the article's purpose had to be to investigate teachers' SRL practice.

\section{Literature Search}

Our search was conducted in the databases PsycInfo, ERIC, and Google Scholar, and we combined the keywords teacher, classroom observation, and self-regulated to search for in the whole article. We included recent literature published in the last three decades, as the most cited models of SRL have been published since the year 1990 (see Panadero 2017). Thus, we restricted our search to studies published between 1990 and 2019. Only studies published in peer-reviewed journals as well as in English language were included in the review. The initial search produced 3710 hits that were scanned based on title and abstract whether they meet the eligibility criteria. From this first screening, 20 studies were considered for meeting the criteria and were submitted to a more systematic coding. To this end, we read the whole article in order to decide whether the study was suitable. This more systematic sorting delivered 17 studies that used systematic observation methods to investigate teachers' attempts to foster SRL and provided quantitative or qualitative data. Other studies had to be sorted out for several reasons. Some articles did not provide data about classroom observations needed for our analyses (e.g., Lau 2012); others did not focus on the SRL of the learners, but instead of preservice teachers' own SRL (e.g., Buzza and Allinotte 2013), or the classroom observation addressed students' SRL instead of teachers' promotion of SRL (e.g., Housand and Reis 2008). This relatively small amount of classroom observation studies in SRL research can be attributed to the high costs of (mostly video-based) observations. Contrary to the research field of teaching effectiveness, where video-based classroom observation has been established successfully as a research method (e.g., Hiebert 2003; Hugener et al. 2009; Stigler et al. 2000), self-reports are the primary tools applied to assess SRL and SRL practice (Dinsmore et al. 2008; Perry and Rahim 2011). The 17 retrieved observation studies were based on different conceptual models (e.g., models on SRL, such as Zimmerman (2000), or models on metacognition, such as Verschaffel et al. (1999), were conducted in different school contexts (primary and secondary school; in-service and preservice teachers), in the context of various school subjects, and focused on different instructional approaches. In accordance with the presented framework, these approaches of studies focused on direct strategy instruction, on indirect activation of SRL, or a combination of both approaches.

\section{Method of Analysis}

Following the guidelines by Aveyard (2014), we first derived codes in order to systematically analyze the retrieved studies. To this end, all papers were re-read more in depth, and the 
following information was coded and provided in a review table (see Table 4 and Table 5). Theoretical model, observation instrument, coding categories of observation instrument, student population, content area (school subject), number of observed teachers, number of observed lessons, number of students, multiple data assessment, main findings, more specifically, findings about direct strategy instruction and indirect activation of SRL, as well as strengths and limitations of the study. In the second step, related codes were grouped together into four themes: conceptual information (theoretical model, observation instrument, coding categories), contextual information (student population, content area, number of teachers and lessons), methodological information (multiple data assessment, strengths, and limitations), and main findings. In the third step, we addressed the four identified themes when discussing each of the three research questions.

\section{Results}

\section{General Description of the Studies}

The included observation studies have been carried out in a range of countries (Belgium, Canada, Germany, Hong Kong, USA, Switzerland, The Netherlands), and involved in total 541 teachers and 2318 students. Most of the observation studies have been conducted in the context of mathematics $(k=7)$, while other studies included several subjects with mathematics being part of $(k=6)$, writing $(k=3)$, or physics $(k=1)$. Seven studies investigated primary school classrooms, and 11 investigated secondary school classrooms. On average, a study was based on $M=3.44$ classroom observations, while most studies included only single lessons, and only one study was based on 7-month-long weekly observation (Depaepe et al. 2010). Except for Spruce and Bol (2015), all coding of strategy instruction was based on low-inferent ratings of short time intervals $(30 \mathrm{~s}$ to $1 \mathrm{~min}$ ) in order to capture teaching time relevant to the instruction of metacognitive strategies. Ratings for the indirect activation of SRL were usually based on high-inferent ratings (e.g., Perry 1998; Michalsky and Schechter 2013).

\section{How Do Teachers Attempt to Promote SRL Among Their Students?}

Classroom observation studies differed in their focus on either direct strategy instruction, or indirect activation of SRL, or a combination of both. In the following, the results of this review that addressed teachers' promotion of SRL will be sorted according to the framework presented above.

\section{Teachers' Direct Strategy Instruction}

As one of the first classroom observation studies about teachers' attempts to support students' ways of learning, Moely et al. (1992) investigated the direct strategy instruction of 69 primary school teachers and how this varied as a function of grade level and school subject. As their study was built on models of strategy instruction they assessed teachers' instruction of metacognitive strategies and of cognitive strategies in language arts and math classrooms, as well as in mixed subjects. The observations yielded that teachers' suggestion of strategy use occurred only in $2 \%$ of the observed intervals. As not all of the strategies that Moely et al. (1992) coded were metacognitive, but rather cognitive (e.g., rote learning), the amount of metacognitive strategy instruction was even smaller. With regard to the activation of 


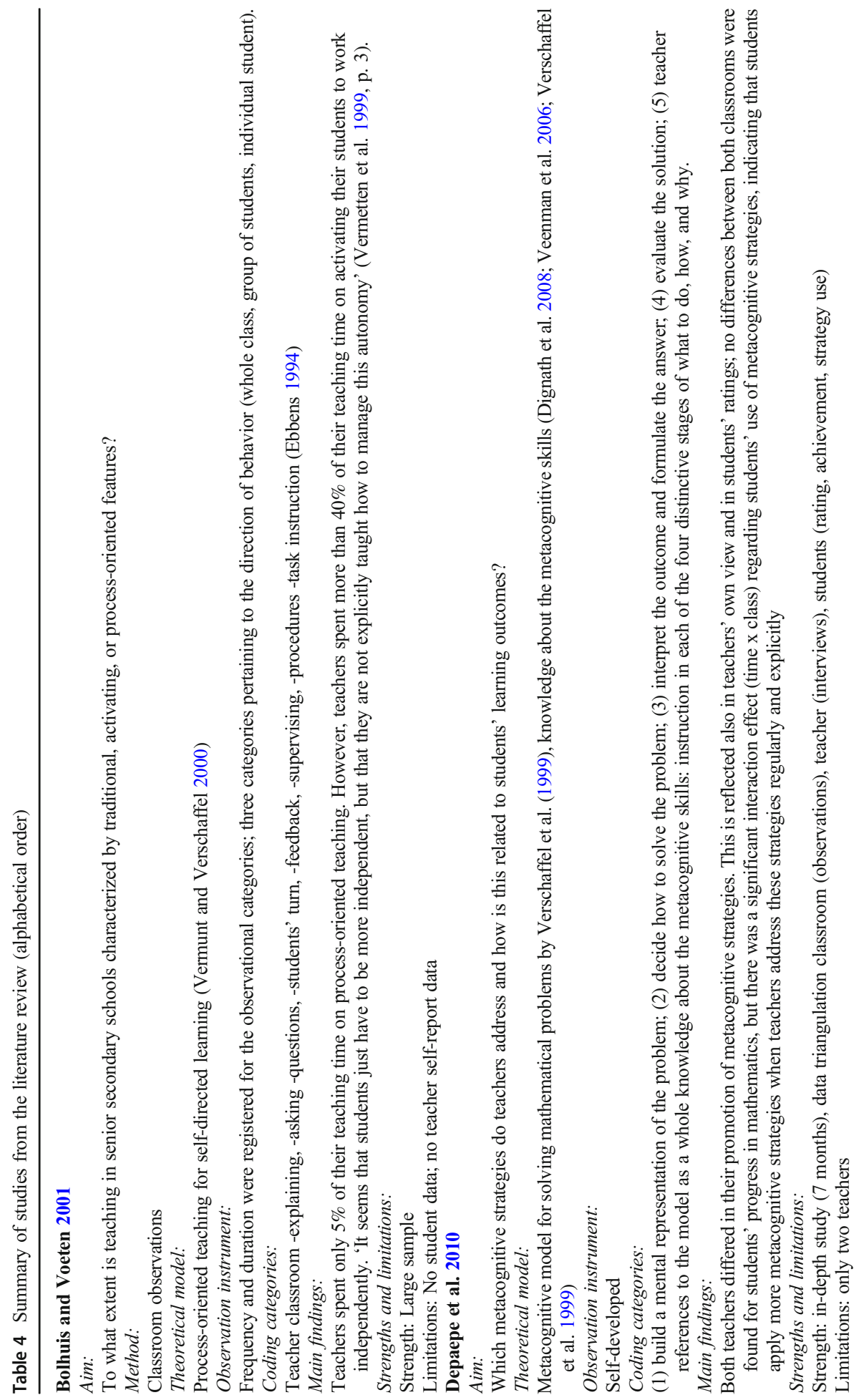


च

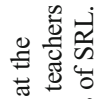

สิ 눈

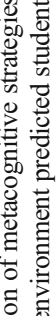

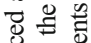

营

记

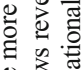

可.

位

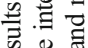

总苜

过

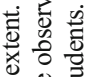

施

要

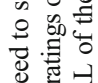

突氜氙

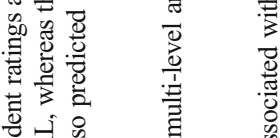

象

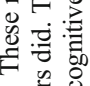

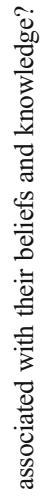

$\dot{\mathrm{s}}$

क्ष

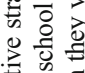

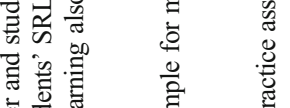

क्षे

过

胥 웜 웅

突总

प)

焉

के

党焉

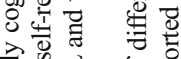

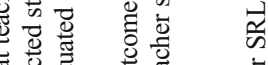

永要

응

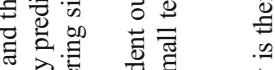

贫岁

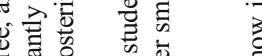

䙳

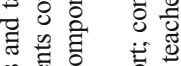

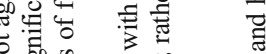

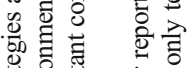

की

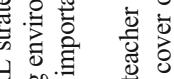

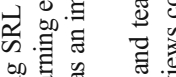

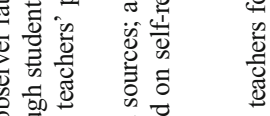

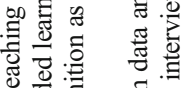

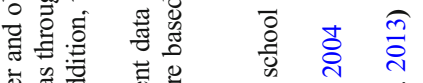

巴ँ

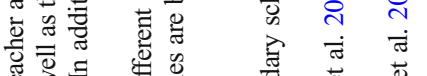

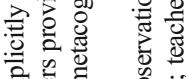

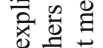




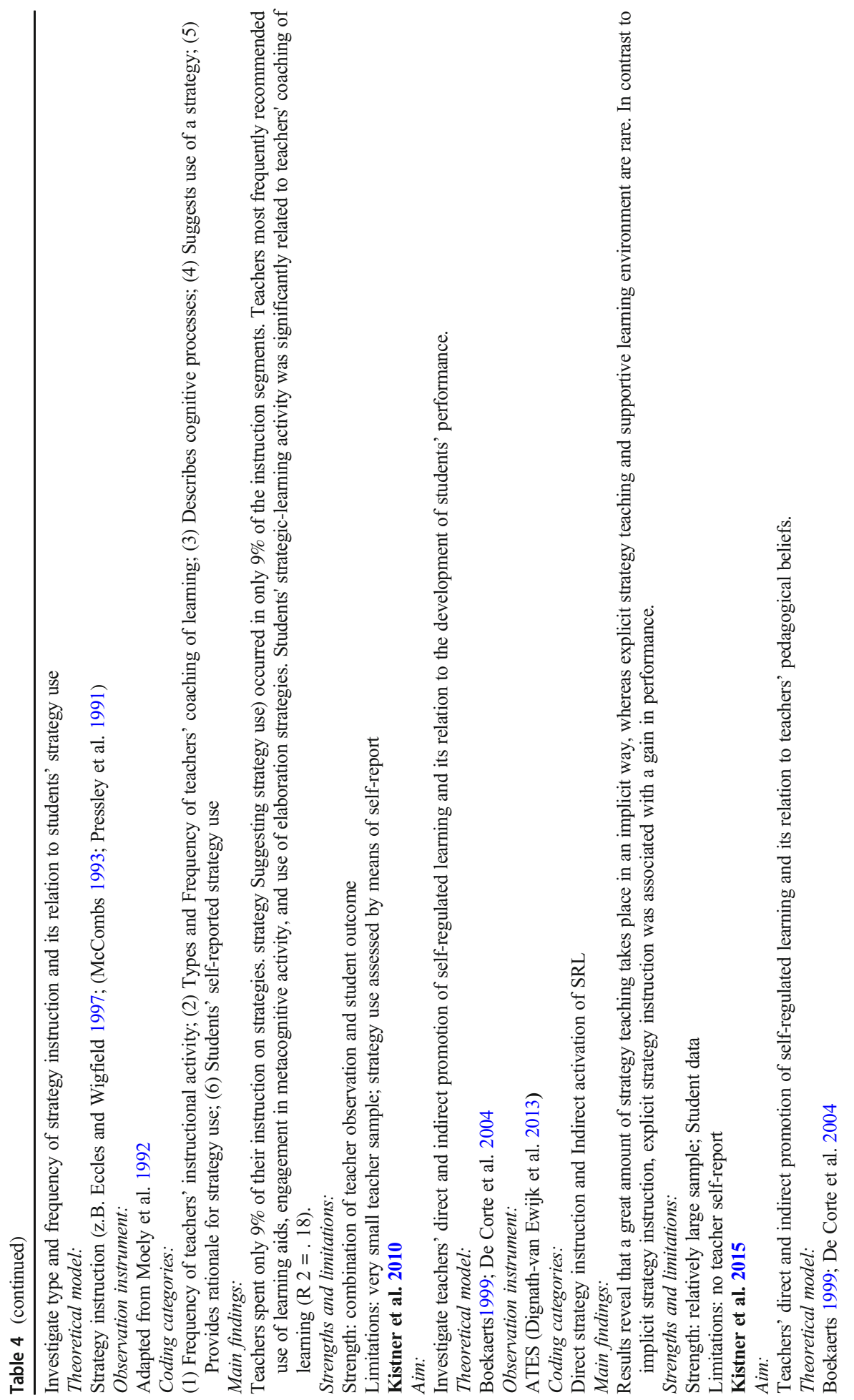




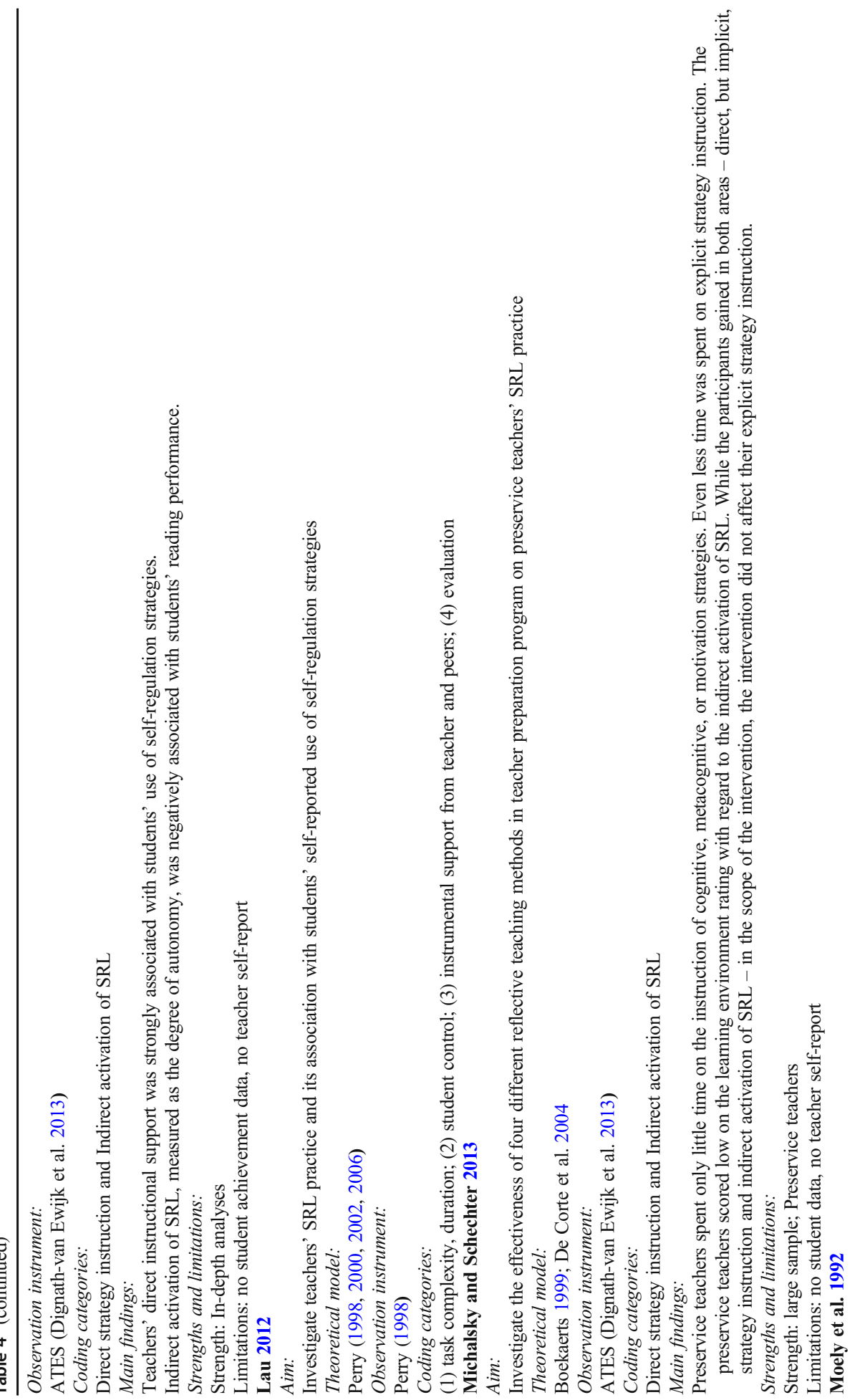




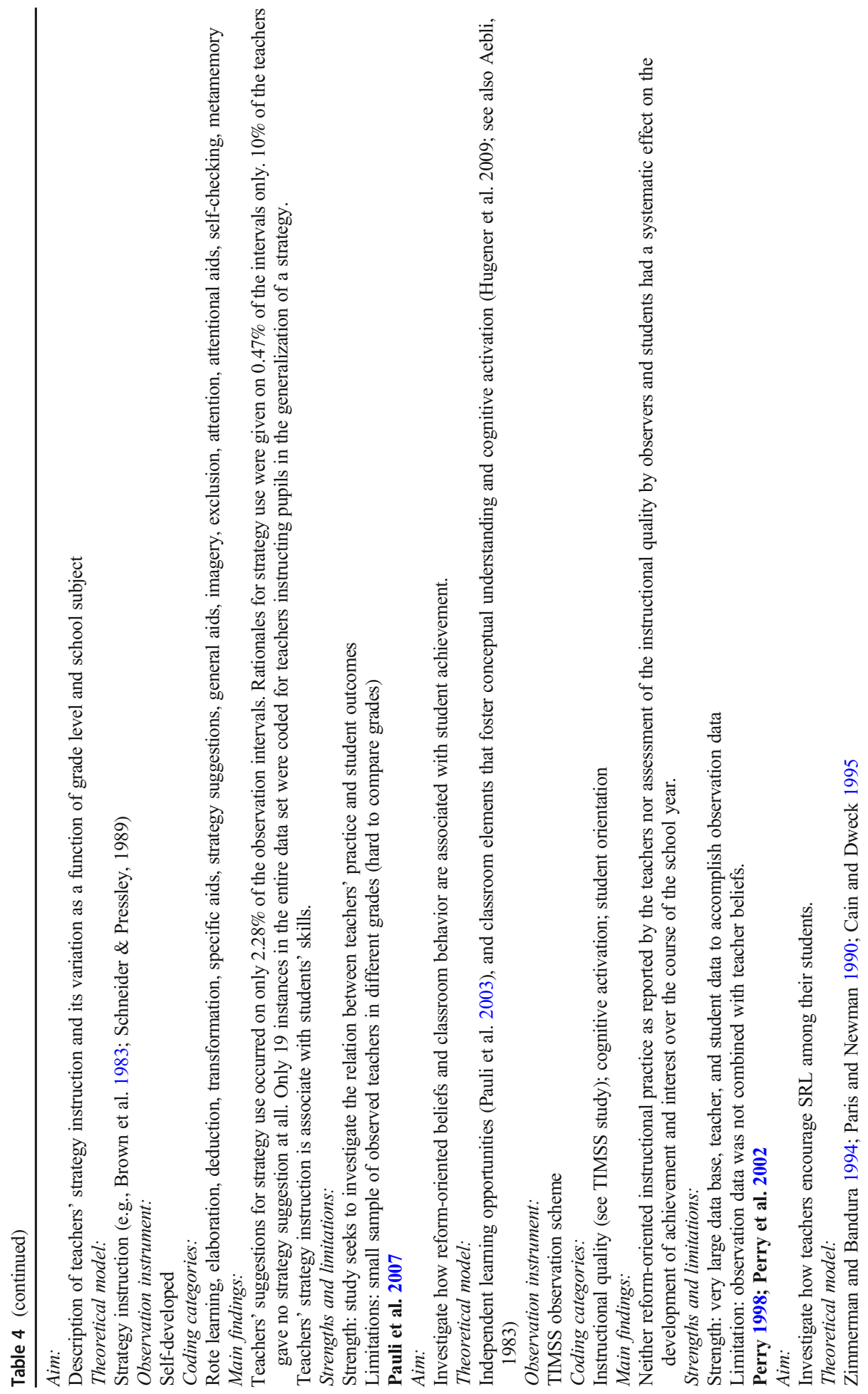




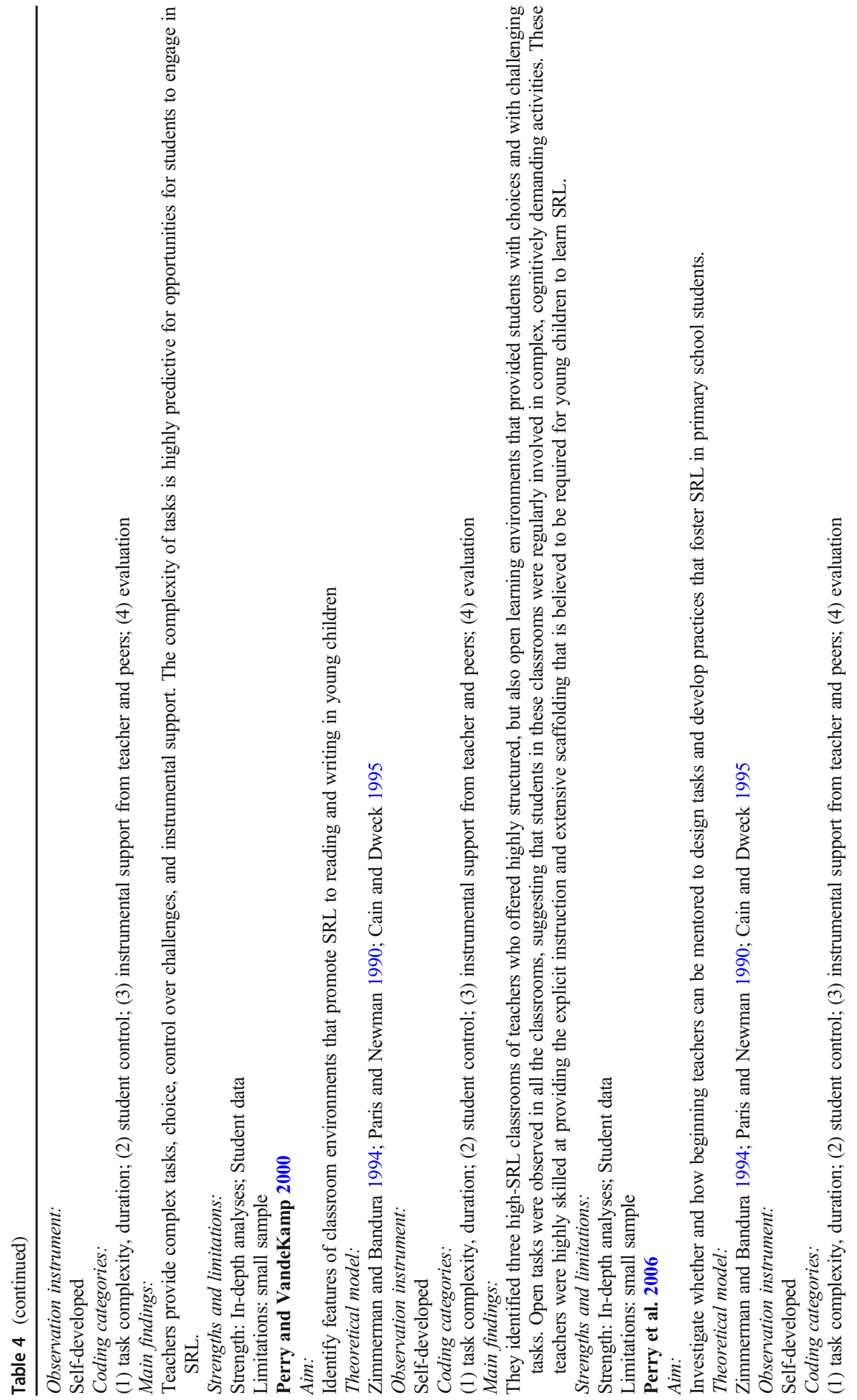




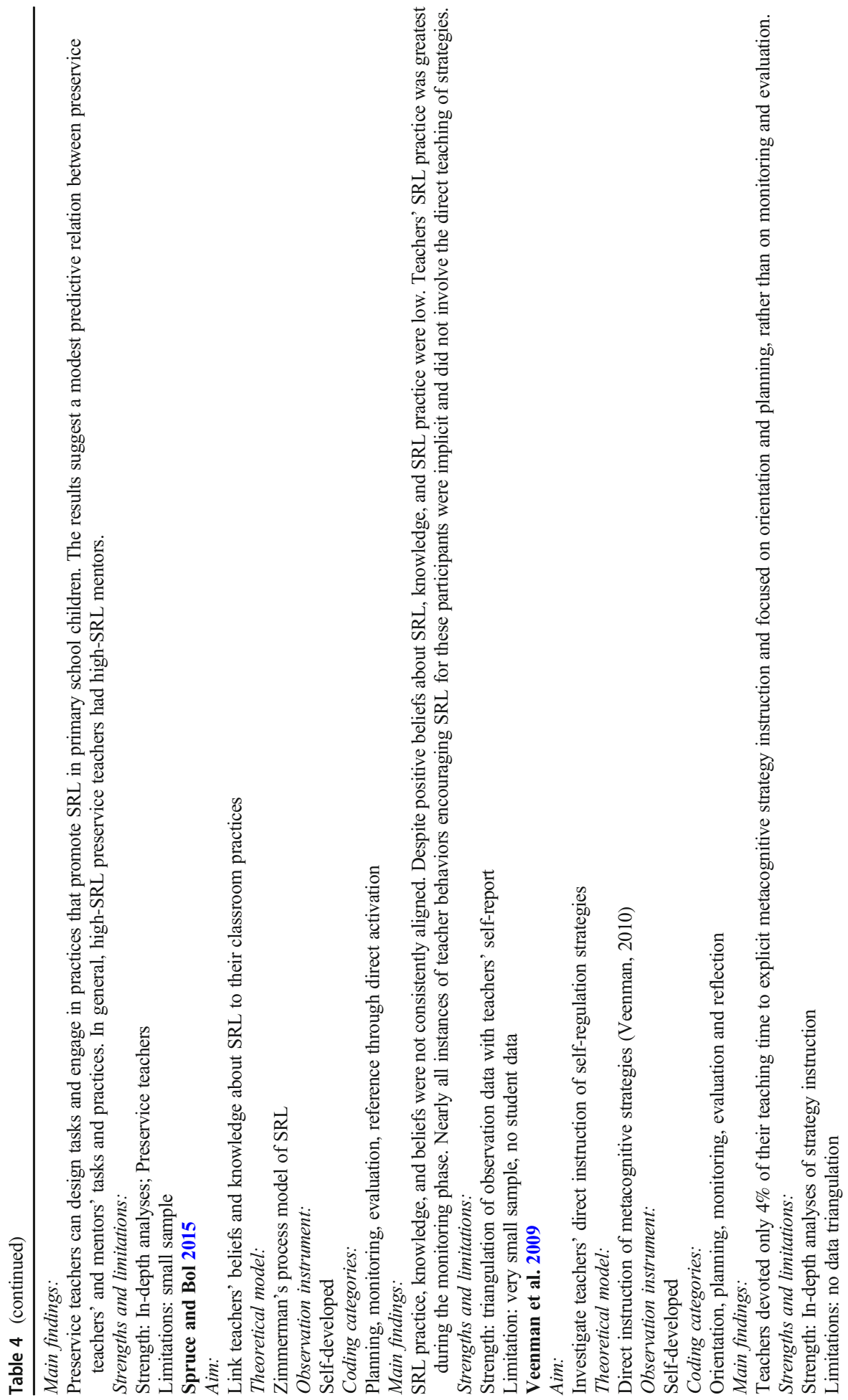




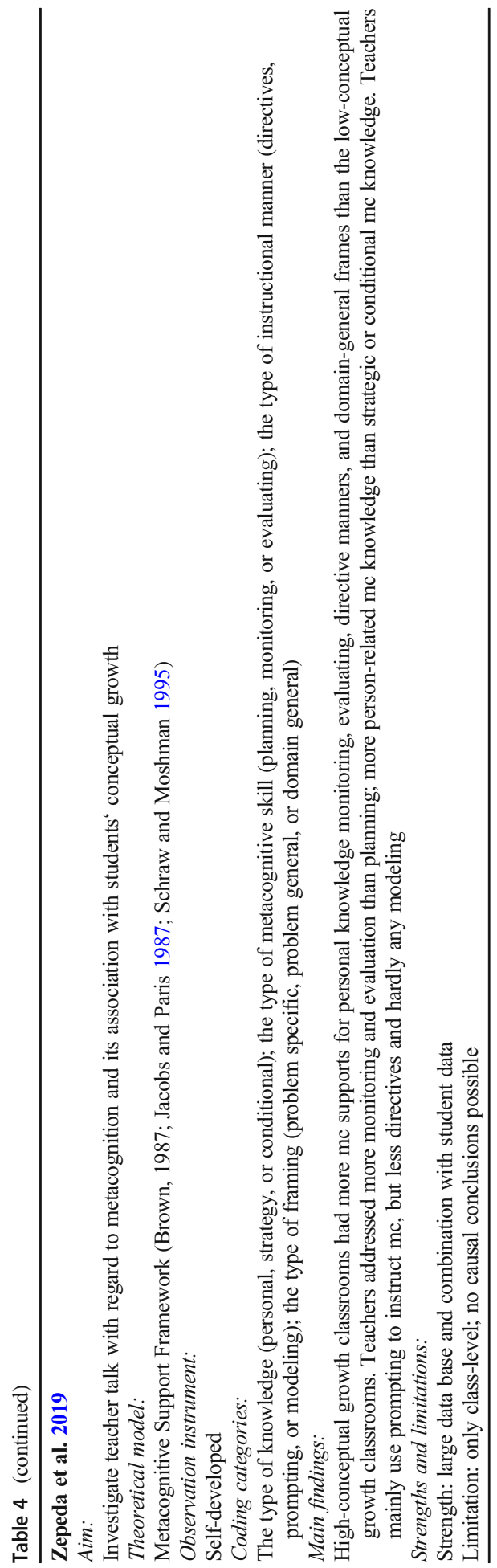




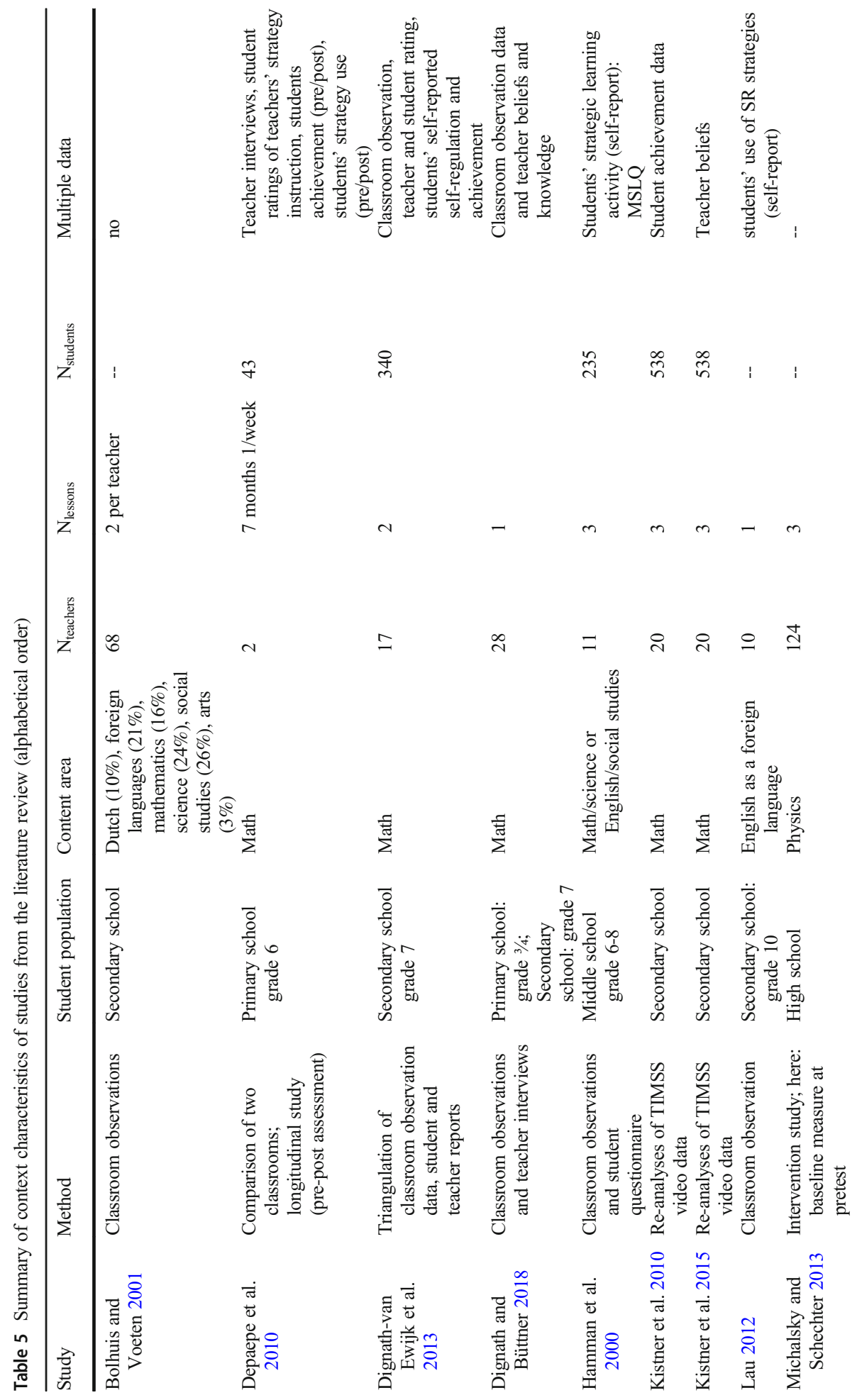




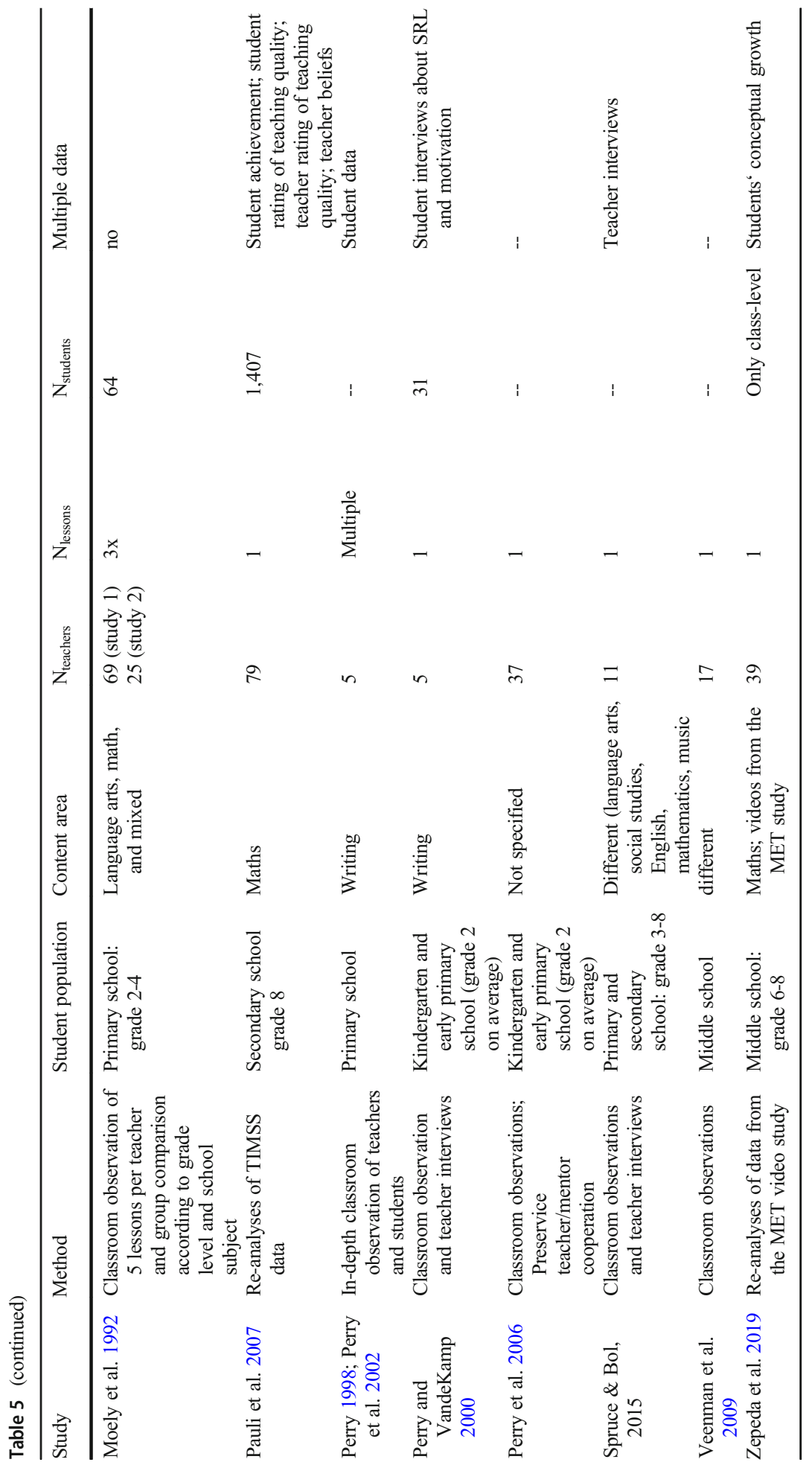


metacognitive reflection about learning, they found that only in less than $1 \%$ of the observed intervals did teachers provide rationales for strategy use. Only 19 instances were coded for teachers instructing pupils in the generalization of strategies. Finally, $10 \%$ of the observed teachers gave no strategy suggestion at all (Moely et al. 1992). Moely et al. (1992) found a significant interaction between grade level and strategy instruction: significantly more strategy instruction was observed in second and third grade than in kindergarten and first grade or in fourth through sixth grade. In a second study, they investigated differences in student performance as a function of teachers' strategy instruction (Moely et al. 1992). These results will be reported on in the next chapter. In an observation study in middle school classrooms, Hamman et al. (2000) adapted the coding scheme by Moely et al. (1992) and extended the coding of teachers' suggestions of strategy use by the types and frequency of what they called "teachers' coaching of learning", which referred to teachers' description of cognitive processes to complete a task, suggestions for strategy use, and explanation of a rationale for why the strategy might be effective. For the 11 middle school teachers who were observed, teaching math, science, English, and social studies in grade 6, 7, or 8, coaching of learning was not found to vary as a function of class grade, school subject, or instructional phase. In line with Moely's observations in primary school classrooms, Hamman et al. (2000) found only 2\% of the instruction segments in middle school to consist of teachers' strategy instruction. While most of the strategies addressed by teachers were cognitive in nature (e.g., rehearsal), only $0.40 \%$ of the total instruction was spent on the instruction of metacognitive strategies, and $0.05 \%$ on the instruction of time management strategies. In addition to classroom observations, Hamman et al. (2000) combined the teacher observations with their students' self-reported strategic learning activity, which will be presented in the next chapter. In line with the results of Moely et al. (1992) and Hamman et al. (2000), Veenman et al. (2009) found similarly low amounts of teaching time devoted to the instruction of metacognitive strategies in secondary school classrooms. They observed a sample of 17 middle school classrooms taught by seven teachers in different disciplines with regard to their instruction of metacognitive strategies. Although a few teachers showed multiple implicit strategy use in their lessons, teachers devoted only $4 \%$ of their teaching time to explicit metacognitive strategy instruction. Moreover, strategy instruction focused on orientation and planning, rather than on monitoring and evaluation (Veenman et al. 2009). The study by Zepeda et al. (2019) aimed at analyzing teachers' metacognitive strategy instruction and at combining this with data of students' learning activity. To this end, they re-analyzed video- and student data that had been gathered in the scope of the MET study (METLDB; Bill and Melinda Gates Foundation 2010) in classrooms from grade 6 through 8 . Next to the instruction of metacognitive strategies, Zepeda et al. (2019) differentiated between metacognitive knowledge and metacognitive strategies to be addressed by the teacher. Their results yielded that only $7 \%$ of the teachers' talk was related to support of metacognition. Furthermore, support of metacognition took place almost five times more often during whole-class instruction than during individual learning phases. Moreover, across all classrooms, teachers supported more monitoring and evaluation than planning; and more personal metacognitive knowledge was addressed than strategy knowledge or conditional knowledge. With regard to teachers' instructional activity when addressing metacognition, more than $80 \%$ of all instructional manners were prompting, but still more directives were provided by teachers than modeling statements. In order to examine how teachers' metacognitive talk is related to class learning outcomes, Zepeda et al. (2019) compared the metacognitive talk of teachers' in low- and high-conceptual growth classrooms (see next chapter). In the same vein, Depaepe et al. (2010) analyzed teachers' instruction of 
metacognitive strategies as well as their statements about metacognitive knowledge. However, rather than analyzing the classroom observations of a single lesson of many teachers, they chose for an in-depth design. In addition to weekly observations in two sixth-grade mathematics classroom for a 7-month-long period, they conducted interviews with the two observed primary school teachers, and assessed the students' problem-solving skills and their mathematics performance. The classroom coding was based on the metacognitive model for solving mathematical problems by Verschaffel et al. (1999). With regard to metacognitive knowledge, Depaepe et al. (2010) also coded separately what to do, how, and why. In line with Zepeda et al. (2019), Depaepe's results revealed that the planning phase was hardly addressed in both teachers' instructional approaches. In general, teachers did not refer to the how and the why aspects of strategy use. Depaepe et al. (2010) found strong differences in the teachers' intensity of referring and using the metacognitive model, which was also reflected in the teachers' own understanding of their classroom practice (teacher interview) as well as in a significant difference between their students' rating of each teacher's use of the metacognitive model during mathematics lessons. Although these results have been based on a very small sample of two teachers and can thus not be generalized, this study produced highly internally valid results as the classroom observations have been conducted over a very long time period of 7 months, and because the data on teachers' promotion of SRL has been triangulated with teacher interviews and student ratings. Moreover, pre- and posttests have been conducted in order to investigate effect of teachers' SRL practice on students' learning progress. These results will be discussed in the next subchapter regarding the second research question. In a similar study, Spruce and Bol (2015) combined classroom observations and teacher interviews to investigate the instructional practice of ten primary and secondary school teachers with regard to their support of SRL. Drawing on Zimmerman's process model of SRL and on the regulatory checklist by Schraw (1998), Spruce and Bol (2015) distinguished between teachers' instruction of metacognitive strategies during the planning phase, the monitoring phase, and the evaluation phase of the SRL cycle. They coded whether, and how often and strongly teachers referred to or directed the activity for such a strategy. The observed teachers activated most SRL among their students during the monitoring phase of learning, but hardly during the planning phase, and even less during the reflection phase of the learning cycle. Moreover, they observed only little direct instruction of metacognitive strategies in the participating classrooms (Spruce and Bol 2015).

\section{Teachers' Indirect Activation of SRL}

Whereas the observation studies described above have investigated the amount of teaching time that teachers devote to metacognitive strategies, other observation studies have focused on the instructional elements that teachers use to activate SRL indirectly. Among the first who investigated the learning environment in real classroom that offer opportunities for SRL, were Perry and her colleagues (Perry 1998; Perry and VandeKamp 2000; Perry et al. 2002, 2006). Perry's $(1998,2000)$ observation scheme included seven categories that distinguish high- and low-SRL environments when coding teachers' speech and actions: (1) types of tasks, (2) types of choice, (3) opportunities to control challenge, (4) opportunities for self-evaluation, (5) support from the teacher, (6) support from peers, and (7) teachers' evaluation practices. The presence and quality of each category in an observed activity were rated on a three-point rating scale (Perry and VandeKamp 2000). The observation studies conducted by Perry showed that three of the five observed primary school teachers provided many learning opportunities to 
their first- and second-grade students, which activated SRL. In particular the complexity of tasks was often associated with the opportunities for students to engage in SRL. These teachers provided their students with complex, cognitively demanding activities, and with the explicit instruction and extensive scaffolding of self-regulation strategies. Likewise, their students were capable of motivating themselves and of regulating their writing process (e.g., Perry and VandeKamp 2000). Perry et al. (2006) expanded Perry's observation research by investigating whether and how preservice teachers can be mentored to design tasks and develop practices that foster SRL in primary school students. To this end, they reported the results of the first 2 years of a 4-year long intervention study with dyads consisting of 37 preservice teachers and their 37 mentors. Classroom observations indicated that many preservice teachers were capable of designing tasks and implementing practices conducive to SRL. Moreover, the complexity of the tasks was strongly predictive of opportunities for students to develop and engage in SRL (Perry et al. 2006). Focusing on classrooms for older students, Bolhuis and Voeten (2001) conducted classroom observations to investigate how secondary school teachers enacted their teaching with regard to process-oriented teaching for SRL (Vermunt and Verschaffel 2000). Among the 68 secondary school teachers, who had each been observed twice in grade 10-12 classrooms, more than $40 \%$ of the teaching time was spent on activating students to work independently, while only $5 \%$ of the total amount of time was spent on process-oriented teaching, i.e., explaining, asking questions, giving feedback concerning the learning process, and providing students with strategies for SRL. Accordingly, most teachers provided their students with learning environments that required SRL, but only little activation of SRL was observed. Bolhuis and Voeten (2001) stress the general problem that "it seems that students just have to be more independent, but that they are not explicitly taught how to manage this autonomy" (Vermetten et al. 1999, p. 3).

\section{Teachers' Direct Strategy Instruction and Indirect Activation of SRL}

While the studies presented earlier focused on either direct strategy instruction or indirect activation of SRL, some classroom observation studies explored teachers' direct instruction of strategies as well as their indirect activation of SRL by providing their students with learning opportunities that foster SRL. These studies can offer new insights into the interplay between both - the direct instruction of metacognitive strategies and the learning opportunities that allow students to self-regulate - and allow investigating when teachers apply which approach to foster SRL, and, ideally, how this is related to student outcomes. Kistner et al. (2010) investigated secondary school teachers' promotion of SRL by re-analyzing 20 video-taped mathematics classrooms from the Swiss-German TIMSS video study (Klieme et al. 2009). The results revealed that on average, only one-tenth of all observed strategy instructions during a lesson focused on metacognitive strategies. The overarching part of incidents, in which teachers addressed strategies, referred to cognitive learning strategies (Kistner et al. 2010). Another study that investigated teachers' direct and indirect promotion of SRL and its associations with student outcomes was conducted by Dignath-van Ewijk et al. (2013), who observed how secondary school teachers fostered SRL in 17 seventh-grade mathematics classrooms and investigated how their activation of SRL would predict their students' achievement, and also their students' SRL. Like the results by Kistner et al. (2010), the largest part of incidents, wherein teachers addressed strategies, was related to cognitive learning strategies, which were closely linked to the learning content of the lessons. Moreover, the instruction of cognitive strategies took place more than six times more often than the instruction of metacognitive strategies. Additionally, the amount of 
teachers' explicit strategy instruction was so small that no differentiation in the coding procedure had been possible; thus, Dignath-van Ewijk et al. (2013) only reported implicit strategy instruction. Next to teachers' direct — though implicit—strategy instruction, Dignath-van Ewijk and colleagues (2013) investigated how teachers designed their learning environment, revealing that teachers scored only low on cooperative, situated, and problem-based learning, and only reached higher ratings regarding the activation of prior knowledge. Furthermore, teachers were significantly more positive than students and observers about their promotion of SRL, scoring up to one rating point higher than the students on a six-point Likert scale. Despite the different estimation of the level for teachers' SRL practice, for almost all areas, teacher and student ratings correlated significantly, whereas teacher and observer data turned out not to be associated significantly (Dignath-van Ewijk et al. 2013). In another classroom observation study, Dignath and Büttner 2018) compared primary and secondary school teachers' support of SRL in a video study with 28 mathematics classrooms. Again, altogether most teachers spent substantially more time on the instruction of cognitive strategies than that they addressed metacognitive strategies, and hardly any explicit strategy instruction could be observed. As the results demonstrated, primary and secondary school teachers did not differ in the amount of time spent on addressing metacognitive strategies per lesson. However, in the seventh-grade secondary school classrooms, substantially more support of cognitive and of motivation strategies was observed than in the third-grade primary school classrooms. Conversely, the primary school teachers scored higher with regard to their indirect activation of SRL, mainly regarding the use of cooperative learning and of constructivist elements of teaching Dignath and Büttner (2018) conclude that while the results indicate that teachers acknowledge SRL somehow, the explicitness of strategy instruction is still missing in regular classrooms. Moreover, the results suggest that teachers address SRL differently in primary and secondary school classrooms. Since the data is correlational, no conclusions can be drawn about whether teachers think that self-regulation is rather for older students, or whether they adapt their strategy instruction to the skills of their students. Nevertheless, the instruction of metacognitive strategies is mainly lacking in both age groups (Dignath and Büttner 2018). Michalsky and Schechter (2013) used classroom observations in order to evaluate the effectiveness of a professional development course during the practicum phase of 124 preservice teachers training. For this review, we were only interested in the baseline measure of all groups that took place prior to the intervention. The preservice teachers spent less than $3 \%$ of the lesson on the explicit instruction of metacognitive strategies, but twice as much on the implicit instruction of metacognitive strategies. The participants spent slightly more time on the instruction of motivation and cognitive strategies. Altogether, only little explicit strategy instruction was observed. Concerning the indirect activation of SRL, the classroom observations revealed that the preservice teachers applied cooperative learning methods to a certain extent, but they did not provide a very constructivist or student-directed learning environment, and did not specifically account to foster transfer of learning (Michalsky and Schechter 2013). Combining the results of these four observation studies reveals that in-service and preservice teachers had comparably low scores regarding their indirect activation of SRL, promoted strategies rather implicitly, and mainly focused on the instruction of cognitive strategies compared to motivation strategies or metacognitive strategies, although the amount of time spent on cognitive strategy instruction was substantially higher in the mathematics classrooms of the observed in-service teachers (see Dignath-van Ewijk et al. 2013; Dignath and Büttner 2018; Kistner et al. 2010) than in the science classrooms of the observed preservice teachers (Michalsky and Schechter 2013). This difference could be due to teachers' experience, but also due to the observed school subject, 
as mathematical learning content often includes mathematical heuristics, thus cognitive strategies.

\section{How Is Teachers' SRL Practice Related to Student Outcomes?}

In order to address this research question, in some of the reviewed studies, additional student data of the observed teachers had been gathered (e.g., Hamman et al. 2000), while others divided classrooms into two groups, either based on student or teacher characteristics, and compared teachers' SRL practice as a function of students' learning gains (e.g., Zepeda et al. 2019) or students' performance as a function of teachers' SRL practice (e.g., Moely et al. 1992). To this end, Moely et al. (1992) investigated whether students' performance in a memory task would vary as a function of their 25 teachers' low or high tendency to suggest strategic activities during learning. The results showed that for high achieving children, the amount of teachers' strategy instruction did not affect their results in the memory task; they benefitted from a short training session for the recall task and showed a good memory task performance in the posttest. However, for the group of low or moderate achievers, children whose teachers rarely offered strategy suggestions showed little improvement and performed poorly in the posttest, whereas for students whose teachers were high in strategy suggestions, achievement differences did not play a role for students' recall scores. The authors conclude that teachers' strategy instruction has an impact on children's skill (Moely et al. 1992). Hamman et al. (2000) came to similar results, showing that teachers' coaching of learning was positively associated with students' self-reported strategy use. However, while students' use of certain cognitive strategies was found to significantly predict teachers' coaching of learning, no association was found between teachers' observed coaching of learning and students' self-reported use of metacognitive strategies. Zepeda et al. (2019) came to similar conclusions, comparing teachers' observed instruction of metacognitive strategies in 20 highconceptual growth classes with that in 19 low-conceptual growth classes. As expected, they found that the support of metacognitive strategies within teacher talk differed between highand low-conceptual growth classes in the way that high-conceptual growth classrooms had more support of using metacognitive strategies regarding monitoring and evaluation strategies than low-conceptual growth classrooms, except for planning. Although the authors observed significantly more personal metacognitive knowledge statements about one's abilities and understanding in high-conceptual growth classes, marginally more conditional metacognitive knowledge statements about when and why to apply strategies - were given in low-conceptual growth classes. Finally, no differences in the activation of strategy knowledge were found. Regarding the instructional manner, the results indicated that teachers used more directive talk in the high-conceptual growth classes and marginally more modeling statements in the lowconceptual growth classes. The authors argue that as more metacognitive talk has been found in high-conceptual growth classrooms, this could indicate the positive effect of metacognition on students' conceptual growth (Zepeda et al. 2019). However, as in the study by Hamman et al. (2000), no causal conclusions can be drawn as teachers might also adapt their strategy instruction to what teachers think their students' needs are. In their re-analyses of the TIMSS data, Kistner et al. (2010) tested the relationship between teachers' observed direct and indirect promotion of SRL and students' achievement gains for the observed teaching unit. They found a significant correlation of students' learning gains with teachers' explicit strategy instruction, but not with their implicit strategy instruction. Moreover, their findings suggested that students' learning gains were substantially associated with constructivist elements of a 
student-centered learning environment, as well as elements that foster situated learning and transfer, but not with the use of self-directed, independent learning or cooperative settings (Kistner et al. 2010). While this correlational data does not allow to draw causal conclusions, the results indicate that teachers' different efforts to support students' SRL may not be equally beneficial to students' learning gains. Contrary to Kistner et al. (2010), Dignath-van Ewijk et al. (2013) did not find teachers' observed SRL practice to predict students' achievement. However, teachers' observed direct instruction of metacognitive strategies turned out to predict students' self-reported SRL, while teachers' observed indirect activation of SRL negatively predicted students' self-reported SRL. In a similar vein, Depaepe et al. (2010) did not find any differences in learning gains between the two observed classrooms that differed in teachers' intensity of activation of metacognition. Their results showed that students in both classrooms made significant progress in mathematics over the 7-month-long period, but they differed in their use of the metacognitive strategies, indicating that students applied metacognitive strategies more frequently when the teacher regularly stressed what, how, and why to apply a strategy (Depaepe et al. 2010). Drawing on the findings by Perry and colleagues (1998; Perry and VandeKamp 2000), Lau (2012) applied Perry's (1998) observation scheme to examine teachers' SRL practice in secondary school language classrooms in Hong Kong. The analyses of six tenth-grade classrooms suggested that the teachers' direct instructional support was strongly associated with their students' use of self-regulation strategies, as well as with their students' learning motivation, while teachers' indirect activation of SRL, measured as the degree of autonomy, was negatively associated with their students' reading performances (Lau 2012). Driven by bringing together different instructional elements that foster SRL, Pauli et al. (2007) re-analyzed the mathematics classrooms of 79 secondary school teachers from the Swiss TIMSS video study (Hiebert et al. 2003) with regard to classroom elements that provide students with independent learning opportunities on the one hand, and classroom elements that foster conceptual understanding and cognitive activation on the other hand. Against their assumptions, Pauli and colleagues (2007) did not discover any effects of neither independent learning opportunities, nor cognitive activation on the development of students' achievement and interest over the course of the school year. However, they found both instructional elements to be independent of one another, since an increased use of independent learning opportunities did not emerge at the costs of learning opportunities that fostered cognitive activation and conceptual understanding (Pauli et al. 2007).

\section{Which Teacher Characteristics Predict Teachers' SRL Practice?}

Beyond the association between teachers' SRL practice and student outcomes, some studies investigated how specific teacher characteristics are related to their SRL practice by gathering additional self-report data from teachers that can provide insights into teachers' beliefs and concepts about SRL and its promotion. In order to accomplish the information gained from their classroom observations, Depaepe et al. (2010) conducted supplementary teacher interviews, which revealed that teachers' beliefs about the usefulness of a systematic approach affected their strategy instruction positively. Accordingly, teachers' rating the degree of their reference to the metacognitive model in their teaching reflected the results of the classroom observations: the teacher, who rarely addressed metacognition during his teaching, rated his reference to the model as low, while the other teacher, who received high scores in the classroom observations, rated her reference to the model as high (Depaepe et al. 2010). To the same end, Kistner et al. 
(2015) investigated associations between the teachers' instruction of metacognitive strategies, as observed in the TIMSS sample published in an earlier paper (Kistner et al. 2010), and their constructivist beliefs, showing that teachers with more constructivist beliefs addressed more metacognitive planning strategies during their lessons. No associations between teachers' beliefs and any other type of strategy instruction were identified (Kistner et al. 2015). Also re-analyzing TIMSS data, Pauli and colleagues (2007) investigated whether teachers' constructivist beliefs are associated with their provision of opportunities for independent problem-solving and of opportunities for SRL. However, they only performed correlation analyses between teacher beliefs and teachers' self-reported promotion of SRL, but not with the observation data. As both perspectives on teachers' indirect promotion of SRL were significantly associated, this is a proxy for the observed SRL practice. They found a significant association for teachers' constructivist beliefs with teachers' provision of opportunities for independent problemsolving but not with teachers' provision of opportunities for SRL (Pauli et al. 2007). Spruce and Bol (2015) aimed to link teachers' beliefs and knowledge about SRL to their SRL practices in the classroom by combining teacher observations with teacher interviews. As their findings revealed, teacher knowledge, beliefs, and SRL practice were not consistently aligned. Although the ten observed teachers held positive beliefs about SRL, their knowledge of SRL and their promotion of SRL in the classroom were generally low. Most teachers had only a vague idea about SRL as related to monitoring activities, but hardly addressed any planning or evaluation in their explanation of SRL. This was also reflected in their observed SRL practice (Spruce and Bol 2015). Similarly, Dignath and Büttner (2018) did not find teachers' beliefs about SRL to be associated with teachers' observed or self-reported promotion of SRL. Most teachers reported very positive views about SRL, in particular for the instruction of cognitive and of motivation strategies. However, many teachers struggled with an explanation of metacognitive strategies. Although many teachers reported finding the promotion of SRL important, they rated their own strategy instruction rather low, in particular for metacognitive strategies, which was also reflected in their limited strategy instruction in the observed lessons (Dignath and Büttner 2018).

\section{Discussion}

To sum up, the results indicated that teachers focused mainly on the instruction of cognitive strategies, and hardly addressed metacognitive strategies - the most important strategy type to regulate one's learning (Corno 2008) in the classroom. Among the instruction of metacognitive strategies, hardly any strategies from the planning phase were addressed (Depaepe et al. 2010; Spruce and Bol 2015; Zepeda et al. 2019). This goes in line with the fact that hardly any explicit instruction of strategies took place (see Dignathvan Ewijk et al. 2013, Dignath and Büttner 2018; Bolhuis and Voeten 2001; Depaepe et al. 2010; Kistner et al. 2010, 2015; Spruce and Bol 2015). Thus, most teachers in these studies have allocated only a small amount of teaching time to the explicit instruction of metacognitive strategies. Whereas meta-analyses have shown that training self-regulation strategies gets particularly effective when providing learners with conditional metacognitive knowledge about how, when, and why to apply a certain strategy, most of the studies included in this review have indicated that teachers rarely discuss this with their students; and this results was consistent across primary and secondary school 
classrooms (Veenman et al. 2009, 2013, Dignath and Büttner 2018; Depaepe et al. 2010; Hamman et al. 2000; Kistner et al. 2010; Michalsky and Schechter 2013; Moely et al. 1992; Zepeda et al. 2019).

Besides, research on instructional teaching elements for SRL has indicated that there are specific instructional elements, which are conducive to SRL, but not every instructional element that supports students' autonomy is necessarily activating SRL (Perry et al. 2002). Comparable to the results of observation research on strategy instruction, teachers' SRL practice that explicitly addressed students' strategies represented less than $10 \%$ of the teaching time (Bolhuis and Voeten 2001). Moreover-although there are elements that distinguish classrooms of highly self-regulating students from others - no empirical associations between these elements and students' achievement outcomes have been demonstrated yet (Pauli et al. 2007). Contrary to the observation studies that focused on direct strategy instruction, these studies were all based on high-inferent coding to rate the learning environment during or after observation.

When looking at classroom characteristics that could be responsible for the variation in teachers' SRL practice, neither the overall comparison of the studies presented in this review nor the single studies that investigated differences in teachers' SRL practice between different subjects or grades (e.g., Moely et al. 1992; Hamman et al. 2000) suggest that teachers' promotion of SRL differs as a function of the school subject or the school grade. However, most studies that delivered data on this indicated that teachers' promotion of SRL was associated with students' achievement. This could either mean that teachers' promotion of SRL affects students' learning, or that teachers take their instructional decisions with regard to SRL in adaptation to their students' learning and achievement, but independently of students' age.

Beyond the description of teachers' strategy instruction, the results suggest that, on the one hand, teachers' strategy instruction is associated partly with teachers' beliefs about learning (Depaepe et al. 2010; Kistner et al. 2015; Spruce and Bol 2015; c.f., Dignath-van Ewijk et al. 2013, Dignath and Büttner 2018), and, on the other hand, with positive learning outcomes of the students (Hamman et al. 2000; Zepeda et al. 2019). However, more specifically, some studies revealed positive associations with student outcomes only for teachers' explicit strategy instruction (Kistner et al. 2010). Moreover, certain instructional elements, which had been found to be effective for high-quality teaching in general - such as cognitive activation - had been found to be associated with positive student achievement in earlier studies (e.g., Kunter et al. 2013), but in the studies incorporated in this review, this result could not be replicated for all the instructional elements that teachers used to activate SRL, such as cooperative or selfdirected learning.

In order to overcome the validity challenges of teachers' self-report, this review was restricted to studies that assessed teachers' promotion of SRL by means of classroom observation. While this can be considered as a strength to this review study, at the same time this criterion has reduced the amount of studies that were eligible. Consequently, this review is based on a rather small amount of studies, and so the generalizability of the results is limited. More classroom observation in different educational contexts is needed in order to provide a valid overview of studies on teachers' SRL practice, which allows for general conclusions. Second, the studies from this review are all based on single moments of assessment and thus offer only correlational data. Longitudinal studies, in particular quasi-experimental or experimental studies, are needed in order to test a causal relationship between teachers' SRL practice and students' learning outcomes. 


\section{General Discussion}

\section{Summary and Implications}

This paper presented a framework of teaching approaches to promote SRL, derived from empirical evidence published over the last decades, and integrating approaches of direct strategy instruction with more indirect approaches for designing learning environments that support SRL. Based on this framework, we systematically reviewed evidence from 17 classroom observation studies conducted in different school settings, in order to advance research in the field of teachers' promotion of SRL. The findings of these studies were stable across countries, school types, and subjects, and demonstrated that certain attempts by teachers to foster SRL took place. With regard to our first research question about teachers' attempts to promote SRL, the results showed that in most settings, teachers prompted SRL rather indirectly by creating learning environments that required students to regulate their learning. Consistently over all samples, only very little instruction of metacognitive strategies had been registered. Observed strategy instruction focused mainly on cognitive strategies, which is not yet supportive of SRL, and hardly on metacognitive strategies, which would be necessary in order to foster students' SRL. Moreover, teachers' attempts to instruct strategies were mainly implicit (e.g., by modeling the use of a certain strategy without explicit verbalization), but only very few teachers verbalized their actions explicitly. Regarding our second research question, all studies found a positive association between the amount of teachers' instruction of selfregulation strategies and students' use of self-regulation strategies. No, or even negative, associations were found between learning environments that were supposed to activate SRL and students' learning outcomes, if no strategy instruction took place. Concerning the last research question about teacher characteristics that predict teachers' SRL practice, we found inconsistent results: while some studies showed positive associations between teachers' beliefs and their SRL practice, others did not find any significant association. With regard to the state of the art, first of all, our results suggest that there is still a gap of classroom observation studies in this field. Second, all studies that investigated the associations between teachers' SRL practice and student outcomes were purely correlational and do not allow for causal interpretation. Moreover, among the few studies that assessed student outcomes, only few studies also assessed the associations with students' learning outcomes (c.f., Kistner et al. 2010; Zepeda et al. 2019), but most of these studies only investigated the associations with students' use of self-regulation strategies, and almost all studies assessed strategy use by means of self-report (cf Perry and VandeKamp 2000). However, research in the field of SRL has pointed to a strong validity problem when assessing strategy use offline and by means of questionnaire (see, e.g., Veenman and van Cleef 2019). Third, only few studies have investigated teachers' SRL practice and associations with aspects of teacher competence. The few studies, which have assessed teacher variables beyond the classroom observations, either focused on teachers' pedagogical beliefs or their self-efficacy beliefs, but only very little research has addressed teachers' knowledge about SRL and their pedagogical knowledge about how to promote SRL so far (see also Zohar and Barzilai 2013). Thus, the results of our review indicate that there is still a research gap, suggesting to carry out integrative research that addresses various characteristics of learners, teachers, and the classroom simultaneously and with innovative methods.

How are the results of this review related to former evidence in the field of SRL and to theoretical frameworks about the promotion of SRL? In contrast to the SRL practice of teachers 
observed in most of these studies, the literature suggests explicitly addressing when and how to use certain strategies in order to build strategy knowledge, and to clarify the benefit of strategy use in order to motivate the learner for the additional effort (e.g., Brown et al. 1981; Dignath and Büttner 2008; McCombs and Marzano 1989; Veenman 2013, 2017). Such theoretical assumptions are supported by some classroom observation studies, suggesting that the instruction of metacognitive strategies is associated with students' self-regulation competence (Dignath-van Ewijk et al. 2013), and that teachers' explicit strategy instruction is connected with better student achievement (Kistner et al. 2010; Zepeda et al. 2019). Yet, these findings are solely correlational, and most often based on small classroom samples. More large-scale studies, as well as experimental research, are needed in order to test whether explicit strategy instruction is more effective than implicit strategy instruction. In addition, research has indicated that teachers may vary their strategy instruction according to their student population since studies conducted in secondary school classrooms delivered more teaching time spend on strategy instruction than primary school classrooms (e.g., Dignath and Büttner 2018; Hamman et al. 2000; Moely et al. 1992). A similar picture emerged in a comparison of primary school teachers with special education teachers in Belgium, conducted in the classroom observation study by Vandevelde et al. (2016). They found that special education teachers devoted significantly more time to the instruction of metacognitive strategies than regular teachers did. While regular teachers instructed very few metacognitive strategies and many cognitive strategies, special education teachers spent a large amount of their teaching time on instructing metacognitive strategies (Vandevelde et al. 2016). These special education teachers, however, represent an exception to the regular primary and secondary school teachers observed in the included classroom observation studies. These results might suggest that teacher populations differ in their expertise on promoting SRL, based on their experience or their pre-service and in-service training. Special education teachers may have had experiences with students who severely lack SRL competencies and may have developed effective ways in promoting SRL successfully. Regular education teachers, particularly secondary school teachers, might not see the need to provide students with strategic knowledge, although their students could also benefit from an explicit strategy instruction of metacognitive knowledge and skills. Again, these studies are cross-sectional, and it remains unclear as to whether teachers adapt to their students, or whether the differences detected are, for example, due to different teacher training. Differential effects should be investigated in longitudinal studies in order to find out whether teachers distinguish between student populations.

One way to scrutinize the complexity of teachers' SRL practice is to combine classroom observations with data about teachers' thinking (Perry and Rahim 2011). Two of the studies reviewed here have indicated that there is little connection between teachers' observed promotion of SRL and their pedagogical beliefs about SRL and constructivism. In a similar vein, Spruce and Bol (2015) also found teachers' beliefs and knowledge about SRL not to be reflected in their observed teaching. Contrary to this, studies that assessed teachers' SRL practice by means of teacher self-report did find significant associations between teachers' beliefs about SRL and their self-reported promotion of SRL (e.g., Dignath-van Ewijk 2016; Dignath-van Ewijk and van der Werf 2012; Lombaerts et al. 2009; Vandevelde et al. 2012; Yan 2018). On the one hand, this association could be traced back to the fact that both variables are rated by the same person. On the other hand, teachers might rate their general promotion of SRL over a long time span, while classroom observations are based on a small sample of lessons (De Jong and Wersterhof 2001; Kunter et al. 2007). Thus, more research that integrates observation methods and teacher interrogation is needed to clarify in how far teacher beliefs predict their promotion of SRL. 
Having teachers comment on their own classroom videos could help to investigate teachers' intentions and could deliver new insights about teachers' ideas on how to activate SRL.

\section{Future Directions for Investigating Teachers' Promotion of SRL}

What can be learned from these insights and which implications can be drawn? From the research reviewed in this paper, we derive ten cornerstone topics that need further research. While the first three refer to the effectiveness of different elements of teachers' SRL practice, the remaining topics draw on different aspects of teachers' competence to foster SRL effectively.

\section{Systematic Comparison Between Direct and Indirect Support of SRL}

Although there is some evidence indicating the importance of direct strategy instruction (e.g., Kirschner et al. 2006; Dignath-van Ewijk et al. 2013), no research has systematically tested the effects of direct vs. indirect support of SRL yet. One the one hand, experimental research is needed in order to investigate whether learners, who receive direct strategy instruction, outperform those who are provided with learning environments that offer autonomy to the students, as observed in many of the studies reviewed here. On the other hand, researchers investigating teachers' SRL practice should consider results from generic teaching effectiveness research: What can be learned about classroom management, student support, and cognitive activation with regard to the activation and promotion of SRL? And vice versa: in how far might specific instructional elements that support students' SRL explain variance in the effectiveness of the dimensions of teaching effectiveness themselves?

\section{Systematic Comparison Between Explicit and Implicit Strategy Instruction}

With regard to the explicitness of strategy instruction, the empirical outcomes of classroom observation research (e.g., Dignath-van Ewijk et al. 2013, Dignath and Büttner 2018; Kistner et al. 2010; De Smul et al. 2017) deviate from the theoretical suggestions for strategy instruction (Brown et al. 1981; Pressley et al. 1992; Veenman 2017). In order to assume a causal relationship between the explicitness of strategy instruction and the effectiveness for student learning, experimental designs are necessary when researching the effects of strategy instruction. This is a particularly interesting and urgent research question since most observation studies have shown that teachers hardly address metacognitive strategies explicitly (Dignath and Büttner 2018; Hamman et al. 2000; Kistner et al. 2010; Moely et al. 1992).

\section{Focusing on Aspects of Teacher Competence to Foster SRL}

When investigating the effectiveness of teachers' SRL practice, the question arises in how far more effective teachers (regarding SRL) differ from less effective teachers. From research on generic teacher effectiveness, we have learned that different aspects of teacher competence are associated with their teaching practice (e.g., Baumert and Kunter 2013): Teachers' content knowledge, their pedagogical content knowledge, and their pedagogical knowledge play a role for the quality of classroom teaching, as well as their pedagogical beliefs, their motivational orientations, and their own self-regulation (Baumert and Kunter 2013). However, only few studies have addressed teacher knowledge about SRL (e.g., Askell-Williams et al. 2012; 
Glogger-Frey et al. 2018), their beliefs about SRL (Dignath-van Ewijk and van der Werf 2012; e.g., Lombaerts et al. 2009), their self-efficacy to support SRL effectively (e.g., Dignath-van Ewijk 2016; De Smul et al. 2018), or teachers' own self-regulation (e.g., Kramarski and Kohen 2017; Peeters et al. 2014). More systematic research is needed that addresses these aspects of teachers' SRL competence.

\section{Uncovering Teachers' Misconceptions}

A contradiction that could lead to misconceptions among teachers might be the question regarding whether the explicitness of strategy instruction implies that teachers should use a transmissive approach rather than a constructivist one when promoting SRL explicitly (see Bolhuis and Voeten 2001). Like for all other learning content, students need the personal experience with SRL and have to construct their own conception about SRL in order to really master it effectively (Perry and Rahim 2011). Teachers' pedagogical knowledge in the context of supporting SRL has to be founded in constructivist learning theories, even when addressing self-regulation strategies explicitly (Pressley et al. 1992; Zohar and Barzilai 2015). Nevertheless, this must not be mistaken as an argument against explicit strategy instruction. Since SRL is an inherently constructivist concept, teachers might assume that acquiring self-regulation competence rather lies with the student than with the teacher (Dignath-van Ewijk and van der Werf 2012), and that acquiring self-regulation skills is the result of experience rather than of instruction, and should thus be an implicit process (Lawson et al. 2019). In contrast, tacit knowledge about strategic learning should be made explicit in order to be available to the learner (e.g., Veenman 2017). In order to address such potential misconceptions, research should address teachers' concepts of SRL, and align this to their instructional practice to support SRL.

\section{Teachers' Self-Efficacy Beliefs}

With the help of in-depth research, Perry et al. (2008) showed that although teachers support the idea of fostering SRL, they often do not know how to help their students self-regulate. Hence, we have to take into account all possible determinants of teachers' competence to promote SRL, rather than focusing only on teachers' pedagogical beliefs about SRL. As some research findings indicate, teachers' self-efficacy might affect their SRL practice more than their beliefs do (Dignath-van Ewijk 2016; Perry et al. 2008; De Smul et al. 2018).

\section{Teachers' Own Self-Regulation}

Understanding the impact of metacognitive strategies and the importance of explicit instruction might be easier once teachers have become aware of their own SRL and the strategy repertoire that they are using (Kramarski 2008, 2018; Peeters et al. 2014). Research on teachers' own SRL has shown that teachers are more motivated to promote SRL when they are convinced of the effectiveness of self-regulation strategies (Dembo 2001). Moreover, in order to model strategy use, teachers need to be experienced strategy users themselves (Paris and Winograd 2003; Kohen and Kramarski 2018). To become aware of self-regulation strategies, teacher training curricula have to address SRL and strategy use explicitly (Randi 2004) in order to 
develop self-regulating teachers who can then develop self-regulating students later on. However, research has shown that even teacher educators often do not promote SRL among their teacher students (Tillema and Kremer-Hayon 2002), although this would be the first step in creating understanding and awareness among future teachers. Thus, teacher education curricula have to integrate SRL not only as learning content but also as a learning method in order to stimulate teachers' own metacognitive reflection and their own understanding of SRL, even before training preservice teachers in how to promote SRL.

\section{Addressing Prior Knowledge During Training}

Furthermore, intervention research with teachers has to take into account teachers' prior concepts about SRL. By building on teachers' prior knowledge about the importance of fostering SRL indirectly and directly, teacher training has to address the need to apply such teaching methods adaptively. This implies that teachers should be able to estimate whether students are able to cope with the autonomy that the learning environment offers, and what students need in terms of scaffolding and strategy instruction. Next to the learning environment, which is often referred to as the surface structure or sight structure of teaching, teachers should become aware of the underlying structure or deep structure of their teaching (Kunter and Ewald 2016). The latter addresses the interaction between teacher and students and, therefore, includes direct strategy instruction. In order to help students in managing SRL (even those who are weak or unexperienced), teachers need to understand that, for some students, it can be beneficial to learn self-regulation strategies explicitly. This could be realized by addressing the value of the strategy for the students in order to motivate them to apply a strategy and to integrate it into their strategy repertoire. With the aim of training students' metacognitive knowledge and skillfulness, teachers need to know how to address metacognitive reflection on what, when, why, and how to apply strategies effectively (Veenman 2017).

\section{Needs of a Heterogeneous Student Population}

Moreover, more comparative research should be conducted that addresses which type of support is most beneficial for different student populations, such as students at different ages, or students with certain needs, in order to develop self-regulated learners. Research has shown that all students can benefit from explicit strategy instruction (for meta-analyses, see Hattie et al. 1996 and Donker et al. 2014), but little evidence is available to date about the specific needs of heterogeneous student groups when developing academic self-regulation.

\section{Teachers' Instructional Decisions}

From the classroom observation studies presented here, it remains unclear as to whether teachers already knew that their students disposed of sufficient regulation strategies to manage learning environments that allow them to self-regulate. The students of the observed teachers might already have entered the level of self-control (Zimmerman 2002) that allow them to gradually take over the responsibility for their learning and to deliberately practice the use of learning strategies that they have acquired in lessons earlier than those that have been observed. Thus, it would be suitable that teachers offer a learning environment that allows 
the students to perform without the teachers' supervision. From classroom observation data alone, the underlying reasons for the observed teacher behavior remain poorly understood (see Kunter et al. 2007). Future research should inquire about why teachers took the instructional decisions observed in classroom videos in order to align them with theories about selfregulation development.

\section{Teachers' Assessment of Students' SRL}

Finally, the question arises regarding how teachers decide about how to support their students' self-regulation of learning. Ideally, teachers have to diagnose their students' self-regulation skills in order to know about the amount of scaffolding that each individual student needs (Corno 2008). However, research about teachers' competence to assess their students' SRL is still scarce. The few studies conducted in this field indicate that teachers have only a limited knowledge regarding ways to assess their students' self-regulation skills (Michalsky 2017). Since the valid assessment of self-regulation skills still represents a major challenge even for researchers (Panadero et al. 2016), how teachers measure such skills is still poorly understood. Research that addresses this gap is needed in order to learn about teachers' intentions that stand behind their SRL practice and the instructional decisions that they have taken.

Funding Information Open Access funding provided by Projekt DEAL.

\section{Compliance with Ethical Standards}

Conflict of Interest The authors declare that they have no conflict of interest.

Open Access This article is licensed under a Creative Commons Attribution 4.0 International License, which permits use, sharing, adaptation, distribution and reproduction in any medium or format, as long as you give appropriate credit to the original author(s) and the source, provide a link to the Creative Commons licence, and indicate if changes were made. The images or other third party material in this article are included in the article's Creative Commons licence, unless indicated otherwise in a credit line to the material. If material is not included in the article's Creative Commons licence and your intended use is not permitted by statutory regulation or exceeds the permitted use, you will need to obtain permission directly from the copyright holder. To view a copy of this licence, visit http://creativecommons.org/licenses/by/4.0/.

\section{References}

Articles included in the review are marked with an asterisk *

Aebli, H. (1983). Zwölf Grundformen des Lehrens: eine allgemeine Didaktik auf psychologischer Grundlage. Stuttgart: Klett-Cotta.

Aronson, E. (1978). The jigsaw classroom. Oxford: Sage.

Askell-Williams, H., Lawson, M. J., \& Skrzypiec, G. (2012). Scaffolding cognitive and metacognitive strategy instruction in regular class lessons. Instructional Science, 40(2), 413-443.

Aveyard, H. (2014). Doing a literature review in health and social care: A practical guide. Berkshire: Open University Press.

Bandura, A. (1986). Social foundations of thought and action: A social cognitive theory. Englewood Cliffs, NJ: Prentice-Hall. 
Baumert, J., Kunter, M., Blum, W., Brunner, M., Voss, T., Jordan, A., \& Tsai, Y.-M. (2010). Teachers' mathematical knowledge, cognitive activation in the classroom, and student progress. American Educational Research Journal, 47(1), 133-180.

Baumert, J., \& Kunter, M. (2013). The COACTIV model of teachers' professional competence. In M. Kunter, J. Baumert, W. Blum, U. Klusmann, S. Krauss, \& M. Neubrand (Eds.), Cognitive activation in the mathematics classroom and professional competence of teachers (pp. 25-48). Boston: Springer.

Bill \& Melinda Gates Foundation. (2010). Measures of effective teaching project. Retrieved from http://www. metproject.org/

Boekaerts, M. (1999). Self-regulated learning: where we are today. International Journal of Educational Research, 31(6), 445-457.

*Bolhuis, S., \& Voeten, M. J. (2001). Toward self-directed learning in secondary schools: what do teachers do?. Teaching and Teacher Education, 17(7), 837-855.

Brophy, J. (2006). Observational research on generic aspects of classroom teaching. In P. A. Alexander \& P. H. Winne (Eds.), Handbook of Educational Psychology (pp. 755-780). Mahwah, NJ, US: Lawrence Erlbaum Associates Publishers.

Brown, A. L., Campione, J. C., \& Day, J. D. (1981). Learning to learn: on training students to learn from texts. Educational Researcher, 10(2), 14-21.

Brown, A.L., Bransford, J.D., Ferrara, R.A., \& Campione, J.C. (1983). Learning, remembering, and understanding In J.H. Flavell \& E.H. Markman (Eds.), Handbook of child psychology: cognitive development (Vol. 3). New York: Wiley

Butler, D. L. (2002). Individualizing instruction in self-regulated learning. Theory Into Practice, 41(2), 81-92.

Butler, D. L., \& Winne, P. H. (1995). Feedback and self-regulated learning: a theoretical synthesis. Review of Educational Research, 65(3), 245-281.

Butler, D. L., Schnellert, L., \& Cartier, S. C. (2013). Layers of self-and co-regulation: teachers' co-regulating learning and practice to foster students' self-regulated learning through reading. Education Research International, 2013, 1-19.

Buzza, D., \& Allinotte, T. (2013). Pre-service teachers' self-regulated learning and their developing concepts of SRL. Brock Education: A Journal of Educational Research and Practice, 23(1).

Cain, K. M., \& Dweck, C. S. (1995). The relation between motivational patterns and achievement cognitions through the elementary school years. Merrill-Palmer Quarterly (1982-1995), 25-52.

Collins, A., Brown, J. S., \& Holmes, A. (1991). Cognitive apprenticeship: making thinking visible. American Educator, 15, 6-11.

Corno, L. Y. N. (2008). On teaching adaptively. Educational Psychologist, 43(3), 161-173.

De Corte, E., Verschaffel, L., \& Masui, C. (2004). The CLIA-model: A framework for designing powerful learning environments for thinking and problem solving. European Journal of Psychology of Education, 19(4), 365-384.

De Jong, R., \& Westerhof, K. J. (2001). The quality of student ratings of teacher behaviour. Learning Environments Research, 4(1), 51-85.

*De Smul, M., Van Keer, H., Heirweg, S., \& Devos, G. (2017). Exploring diversity in teachers' implementation of self-regulated learning in primary schools: A mixed-method study. Paper presented at the biennial meeting of the European Association for Research on Learning and Instruction (EARLI), Tampere (Finland), August 2017.

De Smul, M., Heirweg, S., Van Keer, H., Devos, G., \& Vandevelde, S. (2018). How competent do teachers feel instructing self-regulated learning strategies? Development and validation of the teacher self-efficacy scale to implement self-regulated learning. Teaching and Teacher Education, 71, 214-225.

Deci, E. L., \& Ryan, R. M. (1985). The general causality orientations scale: Self-determination in personality. Journal of Research in Personality, 19(2), 109-134.

Deci, E. L., \& Ryan, R. M. (1993). Die Selbstbestimmungstheorie der Motivation und ihre Bedeutung für die Pädagogik. Zeitschrift für Pädagogik, 39(2), 223-238.

Dembo, M. H. (2001). Learning to teach is not enough — future teachers also need to learn how to learn. Teacher Education Quarterly, 28, 23-35.

Dembo, M. H., \& Eaton, M. J. (2000). Self-regulation of academic learning in middle-level schools. The Elementary School Journal, 100(5), 473-490.

*Depaepe, F., De Corte, E., \& Verschaffel, L. (2010). Teachers' metacognitive and heuristic approaches to word problem solving: analysis and impact on students' beliefs and performance. ZDM, 42(2), 205-218.

Dignath, C., \& Büttner, G. (2008). Components of fostering self-regulated learning among students. A metaanalysis on intervention studies at primary and secondary school level. Metacognition and Learning, 3(3), $231-264$. 
Dignath, C., Büttner, G., \& Langfeldt, H. P. (2008). How can primary school students learn self-regulated learning strategies most effectively?: a meta-analysis on self-regulation training programmes. Educational Research Review, 3(2), 101-129.

*Dignath, C., \& Büttner, G. (2018). Teachers' direct and indirect promotion of self-regulated learning in primary and secondary school mathematics classes-insights from video-based classroom observations and teacher interviews. Metacognition and Learning, 13(2), 127-157.

*Dignath-van Ewijk, C., Dickhäuser, O., \& Büttner, G. (2013). Assessing how teachers enhance self-regulated learning: A multiperspective approach. Journal of Cognitive Education and Psychology, 12(3), 338-358.

Dignath-van Ewijk, C. (2016). Which components of teacher competence determine whether teachers enhance self-regulated learning? Predicting teachers' self-reported promotion of self-regulated learning by means of teacher beliefs, knowledge, and self-efficacy. Frontline Learning Research, 4(5), 83-105.

Dignath-van Ewijk, C., \& van der Werf, G. (2012). What teachers think about self-regulated learning: Investigating teacher beliefs and teacher behavior of enhancing students' self-regulation. Education Research International, 2012.

Dinsmore, D. L., Alexander, P. A., \& Loughlin, S. M. (2008). Focusing the conceptual lens on metacognition, self-regulation, and self-regulated learning. Educational Psychology Review, 20(4), 391-409.

Dolmans, D. H., De Grave, W., Wolfhagen, I. H., \& Van Der Vleuten, C. P. (2005). Problem-based learning: future challenges for educational practice and research. Medical Education, 39(7), 732-741.

Donker, A. S., De Boer, H., Kostons, D., Van Ewijk, C. D., \& Van der Werf, M. P. C. (2014). Effectiveness of learning strategy instruction on academic performance: a meta-analysis. Educational Research Review, 11, $1-26$.

Ebbens, S. O. (1994). Op weg naar zelfstandig leren, effecten van nascholing: effecten van het schoolverbeteringsproject'Alle leerlingen bij de les!'met een perspectief op de nascholing van docenten ten behoeve van de on. Groningen: Wolters-Noordhoff.

Eccles, J. S., \& Wigfield, A. (1997). Young adolescent development. In J. L. Irving (Ed.), What current research says to the middle level practitioner (pp. 15-29). Columbus, OH: National Middle School Association.

Eccles, J. S., \& Roeser, R. W. (2010). An ecological view of schools and development. In J. L. Meece \& J. S. Eccles (Eds.), Handbook of research on schools, schooling and human development (pp. 24-40). New York: Routledge.

Efklides, A. (2011). Interactions of metacognition with motivation and affect in self-regulated learning: The MASRL model. Educational Psychologist, 46(1), 6-25.

Eilam, B., \& Aharon, I. (2003). Students' planning in the process of self-regulated learning. Contemporary Educational Psychology, 28(3), 304-334.

Finsterwald, M., Wagner, P., Schober, B., Lüftenegger, M., \& Spiel, C. (2013). Fostering lifelong learningevaluation of a teacher education program for professional teachers. Teaching and Teacher Education, 29, $144-155$

Flavell, J. H. (1976). Metacognitive aspects of problem solving. The Nature of Intelligence, 12, 231-235.

Garner, R. (1987). Strategies for reading and studying expository text. Educational Psychologist, 22(3), 299312.

Glogger-Frey, I., Ampatziadis, Y., Ohst, A., \& Renkl, A. (2018). Future teachers' knowledge about learning strategies: Misconcepts and knowledge-in-pieces. Thinking Skills and Creativity, 28, 41-55.

Hadwin, A. F., Järvelä, S., \& Miller, M. (2011). Self-regulated, co-regulated, and socially shared regulation of learning. In D. H. Schunk \& J. A. Greene (Eds.), Handbook of Self-Regulation of Learning and Performance. New York: Routledge.

*Hamman, D., Berthelot, J., Saia, J., \& Crowley, E. (2000). Teachers' coaching of learning and its relation to students' strategic learning. Journal of Educational Psychology, 92(2), 342, 348.

Harris, K. R., Graham, S., \& Santangelo, T. (2013). Self-regulated strategies development in writing: Development, implementation and scaling up. In H. Bembenutty, T. J. Cleary, \& A. Kitsantas (Eds.), Applications of Self-Regulated Learning across Diverse Disciplines: A Tribute to Barry J. Zimmerman (pp. 59-87). Charlotte: Information Age Publishing.

Hattie, J. A., Biggs, J., \& Purdie, N. (1996). Effects of learning skills interventions on student learning: a metaanalysis. Review of Educational Research, 66(2), 99-136.

Hiebert, J., Carpenter, T. P., Fennema, E., Fuson, K., Wearne, D., Murray, H., Oliver, A., \& Human, P. (1997). Making sense: Teaching and learning mathematics with understanding. Portsmouth: Heinemann.

Hiebert, J. (2003). Teaching mathematics in seven countries: Results from the TIMSS 1999 video study. DIaNe Publishing.

Hiebert, J., Gallimore, R., Garnier, H., Givvin, K. B., Hollingsworth, H., \& Jacobs, J. (2003). Teaching mathematics in seven countries. Results from the TIMSS 1999 video study. Washington: Department of Education, National Center for Education Studies. 
Hmelo-Silver, C. E., Duncan, R. G., \& Chinn, C. A. (2007). Scaffolding and achievement in problem-based and inquiry learning: a response to Kirschner, Sweller, and. Educational Psychologist, 42(2), 99-107.

Housand, A., \& Reis, S. M. (2008). Self-regulated learning in reading: Gifted pedagogy and instructional settings. Journal of Advanced Academics, 20(1), 108-136.

*Hugener, I., Pauli, C., Reusser, K., Lipowsky, F., Rakoczy, K., \& Klieme, E. (2009). Teaching patterns and learning quality in Swiss and German mathematics lessons. Learning and Instruction, 19(1), 66-78.

Jacobs, J. E., \& Paris, S. G. (1987). Children's metacognition about reading: Issues in definition, measurement, and instruction. Educational Psychologist, 22(3-4), 255-278.

Kirschner, P. A., Sweller, J., \& Clark, R. E. (2006). Why minimal guidance during instruction does not work: an analysis of the failure of constructivist, discovery, problem-based, experiential, and inquiry-based teaching. Educational Psychologist, 41(2), 75-86.

Kirschner, F., Paas, F., \& Kirschner, P. A. (2009). A cognitive load approach to collaborative learning: united brains for complex tasks. Educational Psychology Review, 21(1), 31-42.

*Kistner, S., Rakoczy, K., Otto, B., Dignath-van Ewijk, C., Büttner, G., \& Klieme, E. (2010). Promotion of selfregulated learning in classrooms: investigating frequency, quality, and consequences for student performance. Metacognition and Learning, 5(2), 157-171.

*Kistner, S., Rakoczy, K., Otto, B., Klieme, E., \& Büttner, G. (2015). Teaching learning strategies. The role of instructional context and teacher beliefs. Journal for Educational Research Online, 7(1), 176-197.

Klieme, E., Pauli, C., \& Reusser, K. (2009). The Pythagoras study: investigating effects of teaching and learning in Swiss and German mathematics classrooms. In T. Janik \& T. Seidel (Eds.), The power of video studies in investigating teaching and learning in the classroom (p. 137e160). Münster: Waxmann.

Kohen, Z., \& Kramarski, B. (2018). Promoting mathematics teachers' pedagogical metacognition: A theoreticalpractical model and case study. In Y. J. Dori, Z. Mevarech, \& D. Baker (Eds.), Cognition, Metacognition, and Culture in STEM Education (pp. 279-305). Cham: Springer.

Kounin, J. S. (1970). Discipline and group management in classrooms. Holt, Rinehart \& Winston.

Kramarski, B. (2008). Promoting teachers' algebraic reasoning and self-regulation with metacognitive guidance. Metacognition and Learning, 3(2), 83-99.

Kramarski, B. (2018). Teachers as agents in promoting students' SRL: Research and implications. In D. H. Schunk \& J. A. Greene (Eds.), Handbook of self-regulation of learning and performance (pp. 223-239). New York: Routledge.

Kramarski, B., \& Kohen, Z. (2017). Promoting preservice teachers' dual self-regulation roles as learners and as teachers: Effects of generic vs. specific prompts. Metacognition and Learning, 12(2), 157-191.

Kramarski, B., \& Michalsky, T. (2010). Preparing preservice teachers for self-regulated learning in the context of technological pedagogical content knowledge. Learning and Instruction, 20(5), 434-447.

Kramarski, B., \& Revach, T. (2009). The challenge of self-regulated learning in mathematics teachers' professional training. Educational Studies in Mathematics, 72(3), 379-399.

Kuensting, J., Kempf, J., \& Wirth, J. (2013). Enhancing scientific discovery learning through metacognitive support. Contemporary Educational Psychology, 38(4), 349-360.

Kunter, M., Baumert, J., \& Köller, O. (2007). Effective classroom management and the development of subjectrelated interest. Learning and Instruction, 17(5), 494-509.

Kunter, M., \& Ewald, S. (2016). Bedingungen und Effekte von Unterricht: Aktuelle Forschungsperspektiven aus der pädagogischen Psychologie. In N. M. Elvany, W. Bos, H. G. Holtappels, M. M. Gebauer, \& F. Schwabe (Eds.), Bedingungen und Effekte guten Unterrichts. Waxmann: Münster.

Kunter, M., Baumert, J., Blum, W., Klusmann, U., Krauss, S., \& Neubrand, M. (2013). Cognitive activation in the mathematics classroom and professional competence of teachers: Results from the COACTIV project. Springer Science \& Business Media: Weinheim.

*Lau, K. L. (2012). Instructional practices and self-regulated learning in Chinese language classes. Educational Psychology, 32(4), 427-450.

Lawson, M. J., Vosniadou, S., Van Deur, P., Wyra, M., \& Jeffries, D. (2019). Teachers' and students' belief systems about the self-regulation of learning. Educational Psychology Review, 31(1), 223-251.

Leidinger, M., \& Perels, F. (2012). Training self-regulated learning in the classroom: development and evaluation of learning materials to train self-regulated learning during regular mathematics lessons at primary school. Education Research International, 2012.

Levin, B. (2003). Approaches to equity in policy for lifelong learning. Education and Training Policy Division, OECD. Paris: OECD.

Limón, M. (2001). On the cognitive conflict as an instructional strategy for conceptual change: a critical appraisal. Learning and Instruction, 11(4-5), 357-380.

Lombaerts, K., De Backer, F., Engels, N., Van Braak, J., \& Athanasou, J. (2009). Development of the selfregulated learning teacher belief scale. European Journal of Psychology of Education, 24(1), 79-96. 
McCombs, B. L. (1993). Learner-centered psychological principles: Guidelines for school redesign and reform. In N. M. Lambert \& B. L. McCombs (Eds.), How students learn: Reforming schools through learnercentered education. Washington, DC: American Psychological Association.

McCombs, B. L., \& Marzano, R. J. (1989). Integrating skill and will in self-regulation: putting the self as agent in strategies training. Teaching Thinking and Problem Solving, 11, 1-4.

McCombs, B. L., \& Marzano, R. J. (1990). Putting the self in self-regulated learning: the self as agent in integrating will and skill. Educational Psychologist, 25(1), 51-69.

*Michalsky, T., \& Schechter, C. (2013). Preservice teachers' capacity to teach self-regulated learning: Integrating learning from problems and learning from successes. Teaching and Teacher Education, 30, 60-73.

*Moely, B. E., Hart, S. S., Leal, L., Santulli, K. A., Rao, N., Johnson, T., \& Hamilton, L. B. (1992). The teacher's role in facilitating memory and study strategy development in the elementary school classroom. Child Development, 63(3), 653-672.

Molenaar, I., Chiu, M. M., Sleegers, P., \& van Boxtel, C. (2011). Scaffolding of small groups' metacognitive activities with an avatar. International Journal of Computer-Supported Collaborative Learning, 6(4), 601624.

Nelson, T. O. (1996). Consciousness and metacognition. American Psychologist, 51(2), 102-116.

Panadero, E., \& Järvelä, S. (2015). Socially shared regulation of learning: a review. European Psychologist, 20(3), 190-203.

Panadero, E., Klug, J., \& Järvelä, S. (2016). Third wave of measurement in the self-regulated learning field: when measurement and intervention come hand in hand. Scandinavian Journal of Educational Research, 60(6), $723-735$.

Panadero, E. (2017). A review of self-regulated learning: Six models and four directions for research. Frontiers in Psychology, 8, 422.

Paris, S. G., \& Newman, R. S. (1990). Development aspects of self-regulated learning. Educational Psychologist, 25(1), 87-102.

Paris, S. G., \& Paris, A. H. (2001). Classroom applications of research on self-regulated learning. Educational Psychologist, 36(2), 89-101.

Paris, S. G., \& Winograd, P. (2003). The Role of Self-Regulated Learning in Contextual Teaching: Principals and Practices for Teacher Preparation. CIERA Archive \#01-03

Pauli, C., Reusser, K., Waldis, M., \& Grob, U. (2003). Erweiterte Lehr- und Lernformen im Mathematikunterricht der Deutschschweiz extended forms of learning and teaching in Swiss mathematics instruction. Unterrichtswissenschaft, 31, 291-320.

Pauli, C., Reusser, K., \& Grob, U. (2007). Teaching for understanding and/or self-regulated learning? A videobased analysis of reform-oriented mathematics instruction in Switzerland. International Journal of Educational Research, 46(5), 294-305.

Peeters, J., De Backer, F., Reina, V. R., Kindekens, A., Buffel, T., \& Lombaerts, K. (2014). The role of teachers' self-regulatory capacities in the implementation of self-regulated learning practices. Procedia-Social and Behavioral Sciences, 116, 1963-1970.

Perels, F., Dignath, C., \& Schmitz, B. (2009). Is it possible to improve mathematical achievement by means of self-regulation strategies? Evaluation of an intervention in regular math classes. European Journal of Psychology of Education, 24(1), 17-31.

Perry, N. E. (1998). Young children's self-regulated learning and contexts that support it. Journal of Educational Psychology, 90(4), 715.

Perry, N. E., \& Rahim, A. (2011). Studying self-regulated learning in classrooms. In D. H. Schunk \& B. Zimmerman (Eds.), Handbook of self-regulation of learning and performance (pp. 122-136). New York: Taylor \& Francis.

Perry, N. E. (1998). Introduction: Using qualitative methods to enrich understandings of self-regulated learning. Educational Psychologist, 37(1), 1-3.

*Perry, N. E., \& VandeKamp, K. J. (2000). Creating classroom contexts that support young children's development of self-regulated learning. International Journal of Educational Research, 33(7-8), 821-843.

*Perry, N. E., VandeKamp, K. O., Mercer, L. K., \& Nordby, C. J. (2002). Investigating teacher-student interactions that foster self-regulated learning. Educational Psychologist, 37(1), 5-15.

Perry, N. E., Phillips, L., \& Hutchinson, L. (2006). Mentoring student teachers to support self-regulated learning. The Elementary School Journal, 106(3), 237-254.

*Perry, N. E., Hutchinson, L., \& Thauberger, C. (2008). Talking about teaching self-regulated learning: Scaffolding student teachers' development and use of practices that promote self-regulated learning. International Journal of Educational Research, 472, 97-108.

Pianta, R. C., \& Hamre, B. K. (2009). Conceptualization, measurement, and improvement of classroom processes: Standardized observation can leverage capacity. Educational Researcher, 38(2), 109-119. 
Pianta, R. C., La Paro, K. M., \& Hamre, B. K. (2008). Classroom Assessment Scoring System ${ }^{\mathrm{TM}}$ : Manual K-3. Paul H Brookes Publishing.

Praetorius, A. K., Klieme, E., Herbert, B., \& Pinger, P. (2018). Generic dimensions of teaching quality: the German framework of Three Basic Dimensions. ZDM, 50(3), 407-426.

Pressley, M., Gaskins, L. W., CuniceUi, E. A., BurdlclL, N. J., Schaub-Matt, M., Lee, D. S., \& Powell, N. (1991). Strategy instnv on at benchmark school: a faculty interview study. Learning Disability Quarterly, 14(1), 19-48.

Pressley, M., Harris, K. R., \& Marks, M. B. (1992). But good strategy instructors are constructivists! Educational Psychology Review, 4(1), 3-31.

Pressley, M., Wharton-McDonald, R., Allington, R., Block, C. C., \& Morrow, L. (2001). A study of effective first-grade literacy instruction. Scientific Studies of Reading, 5(1), 35-58.

Rakoczy, K., Klieme, E., Drollinger-Vetter, B., Lipowsky, F., Pauli, C., \& Reusser, K. (2007). Structure as a quality feature in mathematics instruction of the learning environment vs. a structured presentation of learning content. In M. Prenzel (Ed.), Studies on the educational quality of schools. The final report on the DFG priority programme (pp. 101-120). Waxmann: Münster.

Randi, J. (2004). Teachers as self-regulated learners. Teachers College Record, 106(9), 1825-1853.

Renkl, A., Mandl, H., \& Gruber, H. (1996). Inert knowledge: analyses and remedies. Educational Psychologist, 31(2), 115-121.

Resnick, L. B. (1987). The 1987 presidential address learning in school and out. Educational Researcher, 16(9), 13-54.

Rieser, S., Naumann, A., Decristan, J., Fauth, B., Klieme, E., \& Büttner, G. (2016). The connection between teaching and learning: linking teaching quality and metacognitive strategy use in primary school. British Journal of Educational Psychology, 86(4), 526-545.

Salomon, G., \& Perkins, D. N. (1989). Rocky roads to transfer: rethinking mechanism of a neglected phenomenon. Educational Psychologist, 24(2), 113-142.

Salonen, P., Vauras, M., \& Efklides, A. (2005). Social interaction-what can it tell us about metacognition and coregulation in learning? European Psychologist, 10(3), 199-208.

Schaffer, E. C., Nesselrodt, P. S., \& Stringfield, S. (2014). The contributions of classroom observation to school effectiveness research. In D. Reynolds, B. Creemers, P. S. Nesselrodt, E. C. Shaffer, S. Stringfield, \& C. Teddlie (Eds.), Advances in school effectiveness research and practice (pp. 133-150). Amsterdam: Elsevier.

Scheerens, J., Luyten, J. W., Steen, R., \& De Thouars, Y. C. H. (2007). Review and meta-analyses of school and teaching effectiveness. Enschede: Universiteit Twente.

Schraw, G. (1998). Promoting general metacognitive awareness. Instructional Science, 26(1-2), 113-125.

Schraw, G., \& Moshman, D. (1995). Metacognitive theories. Educational Psychology Review, 7(4), 351-371.

Schunk, D. H. (2008). Metacognition, self-regulation, and self-regulated learning: research recommendations. Educational Psychology Review, 20(4), 463-467.

Seidel, T., \& Shavelson, R. J. (2007). Teaching effectiveness research in the past decade: the role of theory and research design in disentangling meta-analysis results. Review of Educational Research, 77(4), 454 499.

Slavin, R. E. (1995). Best evidence synthesis: An intelligent alternative to meta-analysis. Journal of Clinical Epidemiology, 48(1), 9-18.

Souvignier, E., \& Mokhlesgerami, J. (2006). Using self-regulation as a framework for implementing strategy instruction to foster reading comprehension. Learning and Instruction, 16(1), 57-71.

*Spruce, R., \& Bol, L. (2015). Teacher beliefs, knowledge, and practice of self-regulated learning. Metacognition and Learning, 10(2), 245-277.

Stigler, J. W., Gallimore, R., \& Hiebert, J. (2000). Using video surveys to compare classrooms and teaching across cultures: examples and lessons from the TIMSS video studies. Educational Psychologist, 35(2), 87100.

Tillema, H. H., \& Kremer-Hayon, L. (2002). "Practising what we preach"- teacher educators' dilemmas in promoting self-regulated learning: a cross case comparison. Teaching and Teacher Education, 18(5), 593607.

Van de Pol, J., Volman, M., \& Beishuizen, J. (2010). Scaffolding in teacher-student interaction: a decade of research. Educational Psychology Review, 22(3), 271-296.

Vandevelde, S., Vandenbussche, L., \& Van Keer, H. (2012). Stimulating self-regulated learning in primary education: encouraging versus hampering factors for teachers. Procedia-Social and Behavioral Sciences, 69, $1562-1571$.

Vandevelde, S., Van Keer, H., Heirweg, S., \& De Smul, M. (2016). Do regular and special education teachers differ in the way they promote self-regulated learning?. Paper presented at the 7th biennial meeting of the Special Interest Group (SIG) 16 Metacognition of the European Association for Research on Learning and Instruction (EARLI), Nijmegen, August, 2016. 
Veenman, M. V. J., Haan, N., \& Dignath, C. (2009). An observation scale for assessing teachers' implicit and explicit use of metacognition in classroom settings. Paper presented at the 13th Biennial Conference for Research on Learning and Instruction, EARLI. Amsterdam.

Veenman, M. V. J. (2011). Alternative assessment of strategy use with self-report instruments: a discussion. Metacognition and Learning, 6(2), 205-211.

Veenman, M. V. J. (2013). Training metacognitive skills in students with availability and production deficiencies. In H. Bembenutty, T. Cleary, \& A. Kitsantas (Eds.), Applications of self-regulated learning across diverse disciplines: a tribute to Barry J. Zimmerman (pp. 299-324). Charlotte: Information Age Publishing.

Veenman, M. V. J. (2017). Learning to self-monitor and to self-regulate. In R. E. Mayer \& P. A. Alexander (Eds.), Handbook of research on learning and instruction. $2^{\text {nd }}$ (revised ed., pp. 233-257). New York: Routledge.

Veenman, M. V. J. (2018). Final report talent education-metacognition. Leiden: SCOL.

Veenman, M. V. J., \& van Cleef, D. (2019). Measuring metacognitive skills for mathematics: Students' selfreports vs. on-line assessment methods. ZDM International Journal on Mathematics Education, 51(4), 691701.

Veenman, M. V. J., Elshout, J. J., \& Busato, V. V. (1994). Metacognitive mediation in learning with computer based simulations. Computers in Human Behavior, 10(1), 93-106.

Veenman, M. V. J., Van Hout-Wolters, B. H. A. M., \& Afflerbach, P. (2006). Metacognition and learning: conceptual and methodological considerations. Metacognition and Learning, 1(1), 3-14.

Vermetten, Y., Schellings, G., \& Brand-Gruwel, S. (1999). Keeping afloat in a constructive learning environment. Paper presented at the biennial meeting of the European association for research on learning and instruction (EARLI). Goteborg, Sweden, August.

Vermunt, J., \& Verschaffel, L. (2000). Process-oriented teaching. In R. J. Simons, J. Van Der Linden, \& T. Duffy (Eds.), New learning (pp. 209-225). Dordrecht: Springer.

Verschaffel, L., De Corte, E., Lasure, S., Van Vaerenbergh, G., Bogaerts, H., \& Ratinckx, E. (1999). Learning to solve mathematical application problems: a design experiment with fifth graders. Mathematical Thinking and Learning, 1(3), 195-229.

Volet, S. E. (1991). Modelling and coaching of relevant metacognitive strategies for enhancing university students' learning. Learning and Instruction, 1(4), 319-336.

Vosniadou, S., Ioannides, C., Dimitrakopoulou, A., \& Papademetriou, E. (2001). Designing learning environments to promote conceptual change in science. Learning and Instruction, 11(4), 381-419.

Weinstein, C. E., \& Mayer, R. E. (1986). The teaching of learning strategies. In M. Wittrock (Ed.), Handbook of research on teaching (pp. 315-327). Macillan: New Yourk.

Werth, S., Wagner, W., Ogrin, S., Trautwein, U., Friedrich, A., Keller, S., Ihringer, A., \& Schmitz, B. (2012). Förderung des selbstregulierten Lernens durch die Lehrkräftefortbildung «Lernen mit Plan»: Effekte auf fokale Trainingsinhalte und die allgemeine Unterrichtsqualität. Zeitschrift für Pädagogische Psychologie, 26(4), 291-305.

White, M. C., \& DiBenedetto, M. K. (2015). Self-regulation and the common core: application to ELA standards. Routledge.

Wijnia, L., Loyens, S. M., van Gog, T., Derous, E., \& Schmidt, H. G. (2014). Is there a role for direct instruction in problem-based learning? Comparing student-constructed versus integrated model answers. Learning and Instruction, 34, 22-31.

Yan, Z. (2018). How teachers' beliefs and demographic variables impact on self-regulated learning instruction. Educational Studies, 44(5), 564-577.

Zepeda, C. D., Hlutkowsky, C. O., Partika, A. C., \& Nokes-Malach, T. J. (2019). Identifying teachers' supports of metacognition through classroom talk and its relation to growth in conceptual learning. Journal of Educational Psychology, 111(3), 522-541.

Zimmerman, B. J. (1990). Self-regulated learning and academic achievement: an overview. Educational Psychologist, 25(1), 3-17.

Zimmerman, B. J., \& Bandura, A. (1994). Impact of self-regulatory influences on writing course attainment. American Educational Research Journal, 31(4), 845-862.

Zimmerman, B. J. (1998). Developing self-fulfilling cycles of academic regulation: an analysis of exemplary instructional models. In D. H. Schunk \& B. J. Zimmerman (Eds.), Self-regulated learning. From teaching to self-reflective practice (pp. 1-20). New York: Guilford.

Zimmerman, B. J. (2000). Attaining self-regulation: a social cognitive perspective. In Handbook of selfregulation (pp. 13-39). Academic press.

Zimmerman, B. J. (2002). Becoming a self-regulated learner: an overview. Theory Into Practice, 41(2), 64-70.

Zohar, A., \& Barzilai, S. (2013). A review of research on metacognition in science education: Current and future directions. Studies in Science education, 49(2), 121-169. 
Zohar, A., \& Barzilai, S. (2015). Metacognition and teaching higher order thinking (HOT) in science education: Students' thinking, teachers' knowledge, and instructional practices. In R. Wegerif, L. Li, \& J. Kaufman (Eds.), Routledge international handbook of research on teaching thinking (pp. 229-242). Oxon: Routledge. Zohar, A., Degani, A., \& Vaaknin, E. (2001). Teachers' beliefs about low-achieving students and higher order thinking. Teaching and Teacher Education, 17(4), 469-485.

Publisher's Note Springer Nature remains neutral with regard to jurisdictional claims in published maps and institutional affiliations. 